\title{
J-FRACTURE TOUGHNESS OF POLYMERS AT SLOW SPEED
}

\author{
G.E. HALE and F. RAMSTEINER
}

\section{INTRODUCTION}

This paper concentrates on the application of a multiple specimen resistance curve approach as the basis for measuring the J-fracture toughness of plastics, at slow speeds, i.e. displacement rates of typically $1 \mathrm{~mm} / \mathrm{min}$.

Hence, the principal objectives of this paper are therefore:

1. to outline the theoretical background of the J-integral method;

2. to identify and discuss potential problem areas which must be considered when applying a J-based fracture mechanics approach to plastics;

3. to show how the testing protocol works in practice, by summarising results from a series of interlaboratory comparison test programmes.

The testing protocol for conducting J-crack growth resistance curve tests on plastics is given as an appendix at the end of this paper.

\section{BACKGROUND TO THE J-INTEGRAL METHOD}

To characterise crack instability and crack growth in materials, which deform in an elastic plastic manner, Rice [1] introduced the J-Integral method. He showed that the difference between the external work and the change of the internal potential energy within the area surrounded by an integration line $\Gamma$ can be expressed by the line integral along this line:

where:

$$
J=\int_{\Gamma} w d y-\int_{\Gamma} T \frac{d u}{d x} d s
$$

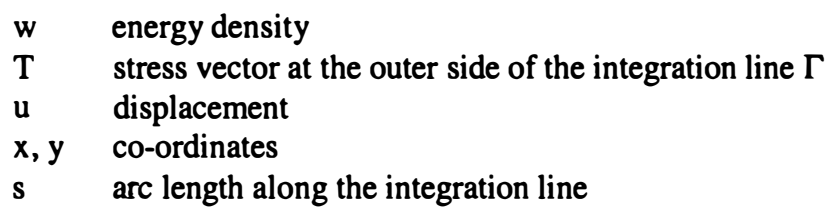

As long as there is no energy dissipation within the area surrounded by $\Gamma$, the value of the integral $\mathrm{J}$ is zero. Any externally applied work is stored elastically in the material. However if the integration line encloses a propagating crack, the value of the J-Integral accounts for the work done per unit area of crack growth. On the basis of this model, J-values are defined by:

$$
J=(1 / B) d U / d a
$$


where:

$$
\begin{array}{ll}
\text { B } & \text { specimen thickness } \\
\text { a } & \text { crack length } \\
\text { U } & \text { total external work }
\end{array}
$$

For practical applications, this leads to equation (1) in 'Introduction to Elastic-Plastic Fracture Mechanics'.

Based on the above definition of the J-Integral for characterising crack growth, it is possible to derive a plane strain condition. Hence this method can only be applied to specimens where:

- the deformation in the third direction can be ignored; e.g. the minimum thickness of the specimens must be large in relation to the yield zone; also the crack length and the distance from the initial notch tip to the specimen surface must exceed minimum values as given in the J-protocol;

- no kinetic effects must be included - this is not critical at low speeds;

- the material temperature remains constant during testing. If significant thermal energy is generated, then Rice's theory is no longer strictly valid as it is based solely on mechanical energy considerations. Hence, values of $\mathrm{J}$ would no longer be geometrically independent, since thermal conductivity and local heating are affected by the specimen shape;

- the applied load must increase steadily; the material should not be unloaded during the test.

Since it is experimentally difficult to observe directly the onset of crack instability, i.e. the point at which the critical value of $\mathrm{J}_{C}$ is defined, extrapolation procedures have been developed to evaluate this value. Begley and Landes [2] used a compliance technique in which several specimens with slightly different crack lengths are deformed. J-values and crack lengths can be evaluated since the compliance of the specimens varies as a function of the crack length. In addition, Landes and co-workers [3] developed a single specimen unloading compliance method for plastics. Finally Landes and Begley [4] used the correlation as given in equation (2) to develop a multiple-specimen resistance curve method, which forms the basis of th: ESIS protocol for measuring the J-fracture toughness of plastics (see Appendix).

\section{PROBLEMS ASSOCIATED WITH THE DEVELOPMENT OF THE TEST PROTOCOL}

\subsection{Crack Growth Measurement}

Early work by the ESIS group indicated that measurement of crack growth $\Delta \mathrm{a}$ is one of the major factors which controls the effectiveness of this test method. While the initial crack length $\left(a_{0}\right)$ can be determined relatively easily, accurate definition of the final crack front position is more difficult. Experimental work by a variety of laboratories demonstrated that two inter-related factors have a major effect on crack length identification after testing: 
- accurate interpretation of features on the fracture face arising as a result of the various deformation mechanisms which occur in different polymers;

- an awareness of features introduced during the breaking-open operation.

Individual laboratories used their own preferred method for marking the crack front after testing. These include:

- cooling the tested specimen in liquid nitrogen or solid carbon dioxide before fracturing at either normal loading rates or at high impact velocities;

- high rate impact fracture at ambient temperature;

- fatigue cycling after the test at either ambient or lower temperatures;

- injection of ink into the crack to mark the front;

- measurement of crack length from polished sections under load (see Fig B 2 in the appendix).

All of these methods have advantages and disadvantages. Cooling in liquid nitrogen may result in the specimen shattering when it is reloaded. In some plastics (e.g. certain grades of HDPE (high density polyethylene)), additional crescent features have been observed close to the crack front with both liquid nitrogen and/or high rate impact loading. This resulted in some laboratories reporting abnormally high values of crack growth. Conversely, impact at room temperature is quick. Ink injection techniques are dependent on using a low viscosity fluid so that it penetrates the crack completely. In materials which craze such as polypropylene with its crystalline lamellae and spherulites, the ink may be drawn into the craze and the precise crack front is then difficult to define. Fatigue cycling gives a definite change in fracture morphology, but it is time consuming especially as the frequency has to be limited to around $10 \mathrm{~Hz}$. Sectioning can be very effective, but it is also time-consuming if used as the only measurement method. Finally, heat-tinting (which is the preferred method for metallic materials) is not effective with thermoplastics.

However, it has been demonstrated that many of the potential problems associated with crack length measurement can be resolved if a limited number of sections perpendicular to the fracture face are prepared and correlated directly with features on the fracture face. This is the approach recommended in the protocol as illustrated schematically in Figure B2.

\subsection{Definition of an Initiation Toughness Parameter}

There is experimental evidence that some form of crack tip blunting occurs in certain thermoplastics as mentioned in 'Introduction to Elastic-Plastic Fracture Mechanics'. For instance, HDPE exhibits blunting at room temperature, whereas at $-20^{\circ} \mathrm{C}$, the crack propagated by voiding and fibril formation, i.e crazing (Fig. 1). Corresponding $\mathrm{J}-\Delta \mathrm{a}$ plots are shown in Fig. 2. At $23^{\circ} \mathrm{C}$, the notch simply deforms by yielding and the J-values follow a $\left(2 \sigma_{y} \Delta a\right)$ blunting line (in agreement with equation (3) in 'Introduction to Elastic-Plastic Fracture Mechanics'). In contrast, at $-20^{\circ} \mathrm{C}$, experimental data at higher values of $\Delta$ a clearly deviate from the blunting line. 


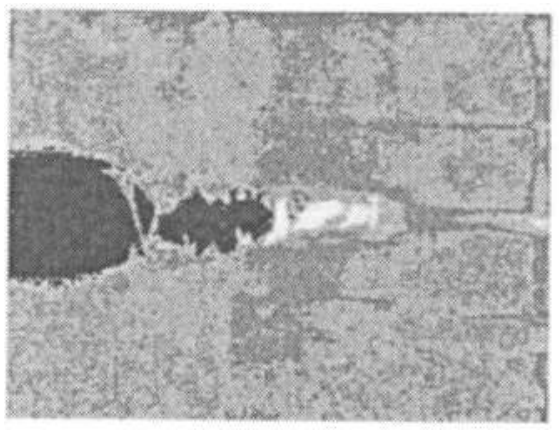

\section{$23^{\circ} \mathrm{C}$}

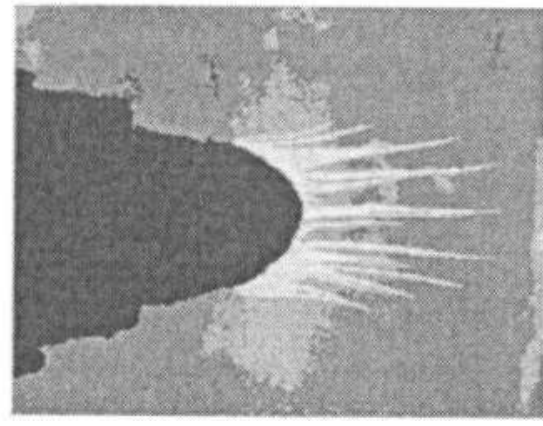

Notch

Fig. 1 Crack tip in a CT-specimen of HDPE (side view) after defonnation at $-20^{\circ} \mathrm{C}$ (crazing) and $23^{\circ} \mathrm{C}$ (blunting)

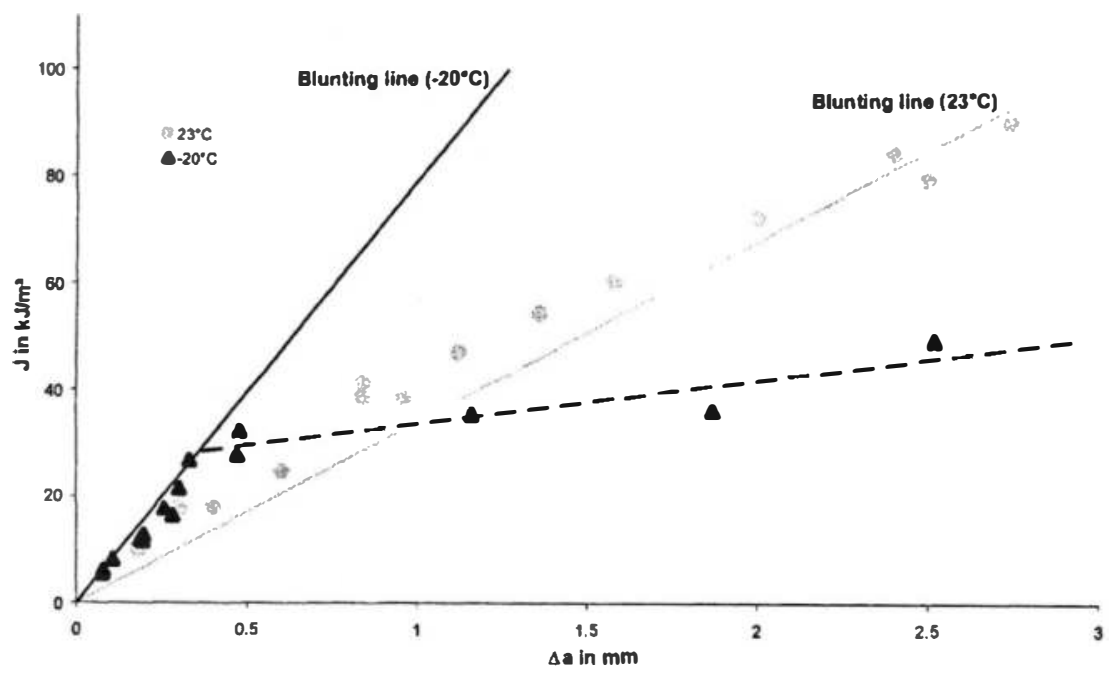

Fig.2 J - $\triangle \mathrm{a}$ diagrams of HDPE, including blunting lines, after testing at -20 and $23^{\circ} \mathrm{C}$

In many cases, experimental observations indicated however that the initial slope of the resistance curve did not coincide with the calculated blunting line or the point of intersection between the blunting line and the remainder of the resistance line was not well defined. Rather, it has been established that the entire J-crack growth resistance curve should be described by a power law $\mathrm{J}=\mathrm{A}(\Delta \mathrm{a})^{\mathrm{N}}$ as discussed in 'Introduction to Elastic-Plastic Fracture Mechanic:s'. This approach was used in the round robin tests described below.

With this approach, the critical $\mathrm{J}_{\mathrm{C}}$-value has been replaced, in most instances, by a pseudoinitiation value $J_{0.2}$, which defines crack resistance at $0.2 \mathrm{~mm}$ of total crack growth. A value of $0.2 \mathrm{~mm}$ is small enough to be close to the point at which the notch becomes unstable and crack initiation commences, but large enough to be experimentally measurable. To allow for 
situations where some form of blunting or multiple cracking does occur, the protocol defines initiation toughness as the lower value of a $\mathrm{J}_{0.2}$ parameter or a $\mathrm{J}_{\mathrm{BL}}$ value (specified as the $\mathrm{J}$-value at the intersection of the blunting line with the $\mathrm{J}-\Delta \mathrm{a}$ curve).

\section{ROUND-ROBIN (INTERLABORATORY COMPARISON) TESTS}

\subsection{Participants and Materials}

Representatives from academic and industrial organisations in Europe and the USA (see Table 1) have collaborated to assess the effectiveness of this test procedure by a series of round robin tests on different polymers.

A transparent ABS (acrylonitrile-butadiene-styrene copolymer) and a modified PVC (polyvinylchloride) were used as amorphous materials. A polyamide blend (rubber modified PA (polyamide) with PPO (polyphenylene oxide) addition), HDPE (high density polyethylene) \{ with a density $\rho=0.944 \mathrm{~g} / \mathrm{cm}^{3}$ corresponding more closely to a MDPE (medium density polyethylene)\}, a PP (polypropylene) homopolymer, and a random ethylene/propylene copolymer were used to study semi-crystalline polymers. Further details of the manufacturer of these thermoplastics, original form and dimensions are given in Table 2.

Table 1 Participants in the ESIS TC4 round-robin programmes on J-testing of plastics

\begin{tabular}{|l|l|}
\hline Organisation & Contributors \\
\hline TWI & G E Hale \\
\hline EMPA & P Flueller, B Wagner \\
\hline Solvay & D Adem, A Goldberg \\
\hline Politecnico di Milano & A Pavan, M Rink \\
\hline Pipeline Developments & P Marshall, Morley, Hepburn \\
\hline Imperial College & J G Williams, W N Chung, H McGillivray, Chan, Breda, \\
\hline ICI & D R Moore \\
\hline Eastman Kodak & E Moskala \\
\hline EAHP & R Schirrer \\
\hline DSM & E H Gaalman, H Bos \\
\hline Du Pont & H E Daeniker \\
\hline Cranfield University & I Partridge \\
\hline BASF & F Ramsteiner \\
\hline BP Chemicals & M Cawood, A J Herningway, A Gray \\
\hline GKSS & E Reese \\
\hline
\end{tabular}


Table 2 Materials used in the round-robin tests

\begin{tabular}{|c|c|c|c|c|}
\hline Material & $\begin{array}{l}\text { Manufacturer/ } \\
\text { Supplier }\end{array}$ & Product Form & Size (mm) & $\begin{array}{c}\text { Yield strength } \\
\text { in tension } \\
(\mathrm{MPa})(1) \\
\end{array}$ \\
\hline ABS & BASF & $\begin{array}{l}\text { Injection moulded } \\
\text { disc }\end{array}$ & $\begin{array}{l}185 \text { diameter } x \\
16 \text { thick }\end{array}$ & 33 \\
\hline $\begin{array}{l}\text { Polyamide blend } \\
\text { ®Ultranyl }\end{array}$ & BASF & $\begin{array}{l}\text { Injection moulded } \\
\text { disc }\end{array}$ & $\begin{array}{l}185 \text { diameter } x \\
16 \text { thick }\end{array}$ & 47.4 \\
\hline Modified PVC & $\begin{array}{l}\text { Pipeline } \\
\text { Developments }\end{array}$ & $\begin{array}{l}\text { Sheet produced by } \\
\text { flattening pipe in a } \\
\text { heated press }\end{array}$ & $450 \times 300 \times 9.5$ & 43.9 \\
\hline Polypropylene & BASF & Extruded sheet & $500 \times 250 \times 15$ & 29.9 \\
\hline HDPE & BP Chemicals & $\begin{array}{l}\text { Compression } \\
\text { moulded plaques }\end{array}$ & $\begin{array}{l}500 \times 500 \text { at } 19 \\
\text { and } 23 \text { thick }\end{array}$ & 23.1 \\
\hline $\begin{array}{l}\text { Ethylene/ } \\
\text { Propylene } \\
\text { random } \\
\text { copolymer }\end{array}$ & ICI & $\begin{array}{l}\text { Centre-gated } \\
\text { injection moulded } \\
\text { discs }\end{array}$ & $\begin{array}{l}150 \text { diameter } x \\
12.5 \text { thick }\end{array}$ & $31.6(2)$ \\
\hline
\end{tabular}

(1) All tests carried out at a loading rate of $1 \mathrm{~mm} / \mathrm{min}$ and at $23^{\circ} \mathrm{C}$, unless stated otherwise

(2) Tested at $2 \mathrm{~mm} / \mathrm{min}$

As the investigations progressed, it became apparent that the thermoplastics studied rnay be grouped into three categories:

- Easy to characterise, e.g. ABS, polyamide blends, modified PVC.

- Plastics where additional crack face features complicate interpretation, e.g. HDPE, polypropylene

- Thermoplastics exhibiting fine-scale fracture face features which make crack growth difficult to measure, e.g. ethylene/propylene copolymers

\subsection{Easy to characterise materials}

ABS is a good example of a thermoplastic where the absence of sidegrooving results in substantial crack front bowing which compounds the presence of a large stress whitened plastic zone ahead of the crack tip. Fig. 3 shows the development of a stress-whitened zone in compact tension (CT) non-sidegrooved specimens of ABS at various points on the deformation curve. Since the material was transparent, it was possible to look at the development of the crack through the sides of the testpiece. At point 4 (see Fig. 3), the specimen was broken open so that the side view of the growing crack in the unbroken testpiece and the actual fracture surface from the same specimen could be compared. The actual crack front is substantially less 
extended than indicated by the position of the stress-whitened zone. The overall effect is to hamper definition of the precise position of the crack front. This resulted in considerable data scatter between different laboratories. Hence, the importance given to the use of a combination of fracture face measurement and sectioning to ensure that an optimal approach to crack growth measurement is adopted.

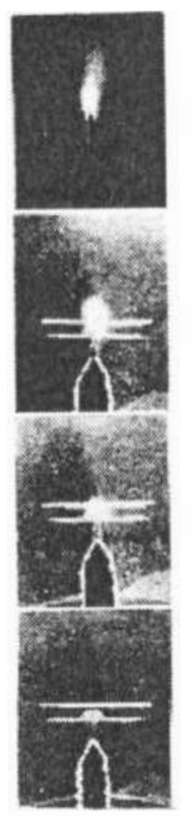

(4)

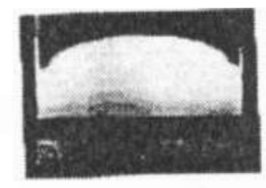

(3)

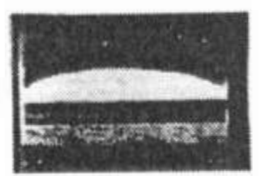

(2)
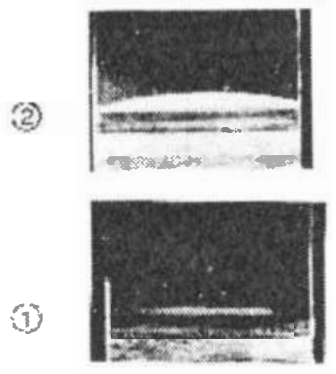

$\stackrel{2}{-1}$

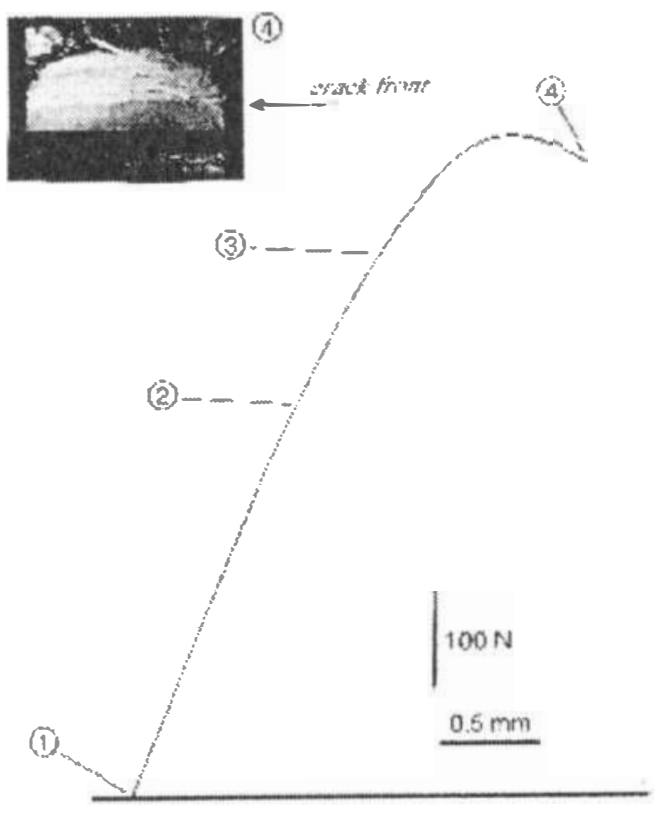

Fig.3 Crack growth development in non-sidegrooved CT specimens of transparent ABS at different points on the deformation curve.

At points 1,2 and 3, the crack was photographed through the sides of the transparent specimen.

At point 4, the specimen was also broken open so that the fracture surface could be compared to the side view of the developing crack.

Considerably less scatter was observed in sidegrooved SENB specimens of ABS (Fig. 4) and the data can be approximated by the power law:

$$
\mathrm{J}=7.35 \Delta \mathrm{a}^{0.49}
$$

where $\mathrm{J}$ is in $\mathrm{kJ} / \mathrm{m}^{2}$ and a is measured in $\mathrm{mm}$.

In this case, $\mathrm{J}_{0.2}=3.35 \mathrm{~kJ} / \mathrm{m}^{2}$. 


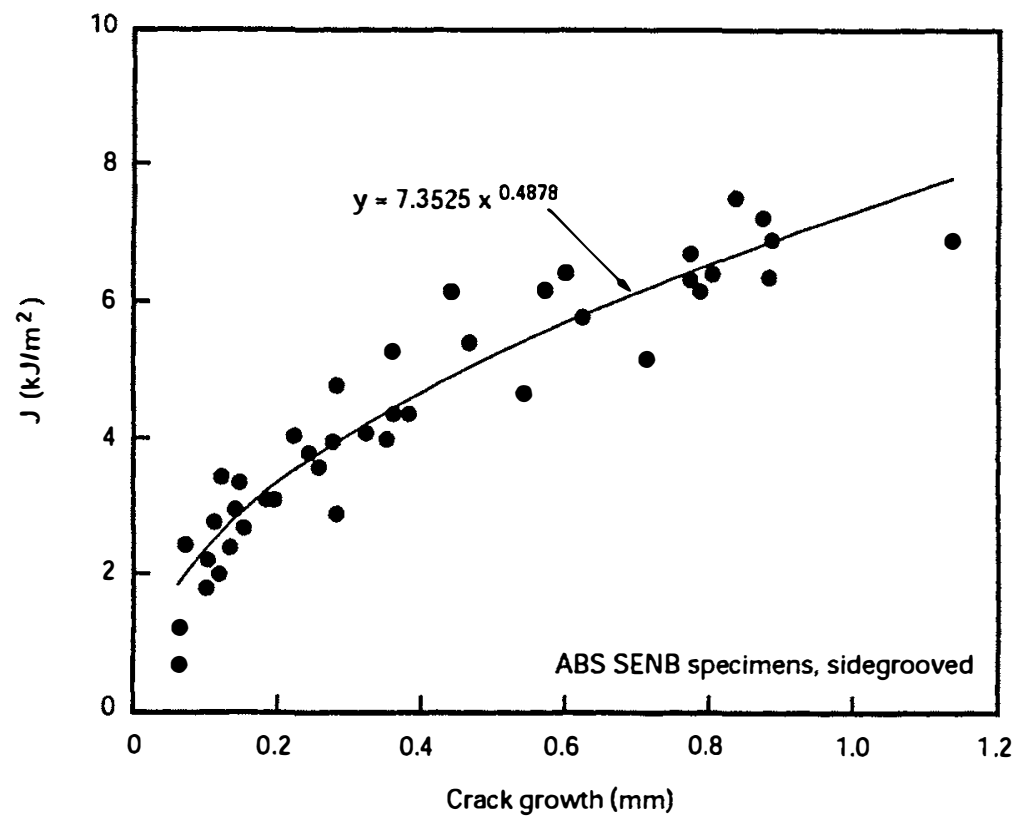

Fig.4 Power law fit to ABS data (side grooved SENB specimens) generated by six laboratories,

Table 3 contains the $\mathrm{A}$ and $\mathrm{N}$ parameters and $\mathrm{J}_{0.2}$ values for six laboratories.

Table 3 Compilation of J R-Curve Data for ABS sidegrooved SENB specimens

\begin{tabular}{|c|c|c|c|c|c|}
\hline Organisation & $\begin{array}{c}\text { Notch sharpening } \\
\text { method }\end{array}$ & $\begin{array}{c}\mathrm{J}_{0.2} \\
\left(\mathrm{~kJ} / \mathrm{m}^{2}\right)\end{array}$ & \multicolumn{2}{|c|}{$\begin{array}{c}\text { Curve-fitting } \\
\text { parameters }\end{array}$} & Comments \\
\hline & & & $\mathrm{A}$ & $\mathrm{N}$ & \\
\hline 1 & $\begin{array}{c}\text { Tapped scalpel } \\
\text { blade }\end{array}$ & 2.78 & 7.62 & 0.626 & \\
\hline & $\begin{array}{c}\text { Sliding carpet knife } \\
\text { blade }\end{array}$ & 2.55 & 8.12 & 0.72 & Very sharp sidegrooves \\
\hline 7 & Tapped razor blade & 3.86 & 8.665 & 0.502 & \\
\hline 8 & Fly cutter & 4.12 & 8.04 & 0.415 & \\
\hline 10 & Tapped razor blade & 3.35 & 6.94 & 0.45 & Only 7 specimens used \\
\hline 14 & Sliding razor blade & 3.3 & 7.32 & 0.493 & \\
\hline
\end{tabular}

Experimental work on a modified PVC indicated that sidegrooving appeared to have a less substantial effect than observed in the studies carried out on ABS. At low levels of crack growth, the amount of scatter between different laboratories is small (Fig. 5). After assessing all the experimental data for PVC, an average value for $J_{0.2}$ is $10.2 \mathrm{~kJ} / \mathrm{m}^{2}$. 


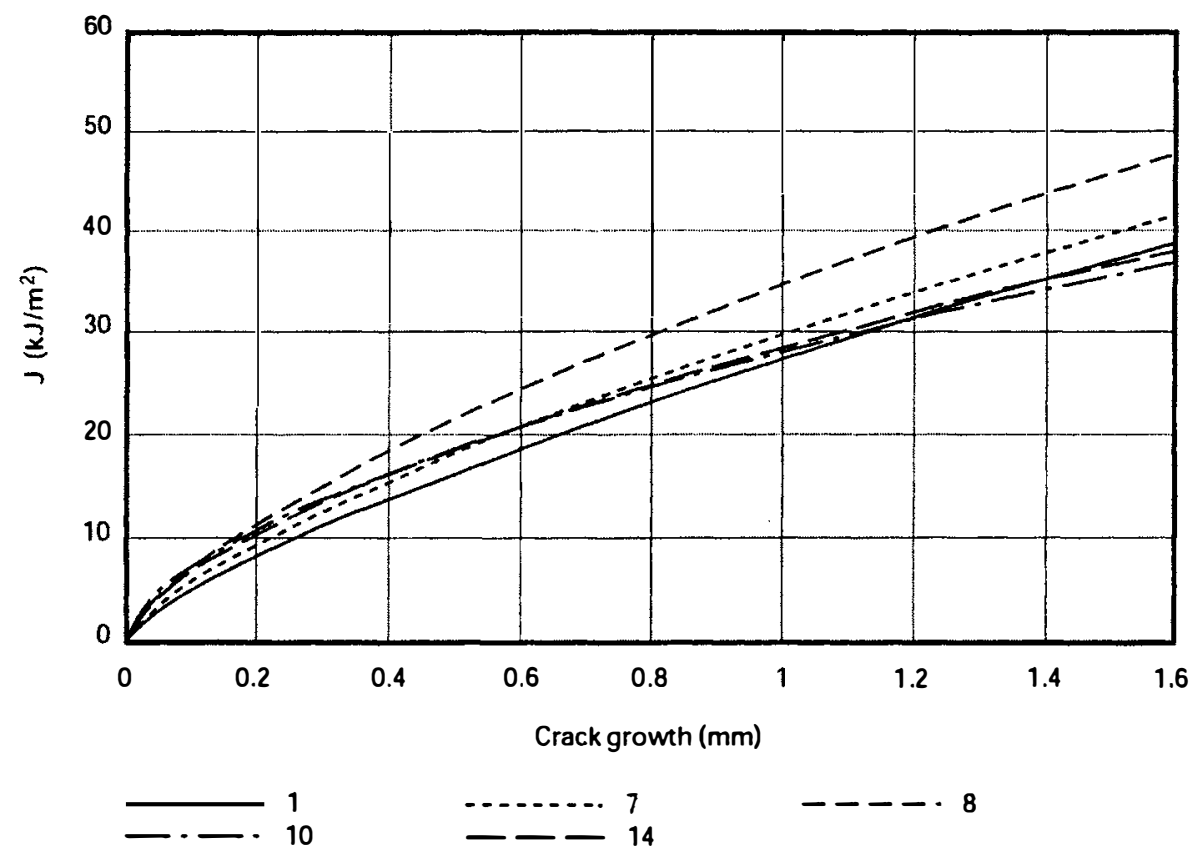

Fig. 5 Comparison of J R-curves for modified PVC (sidegrooved SENB testpieces) measured at five laboratories.

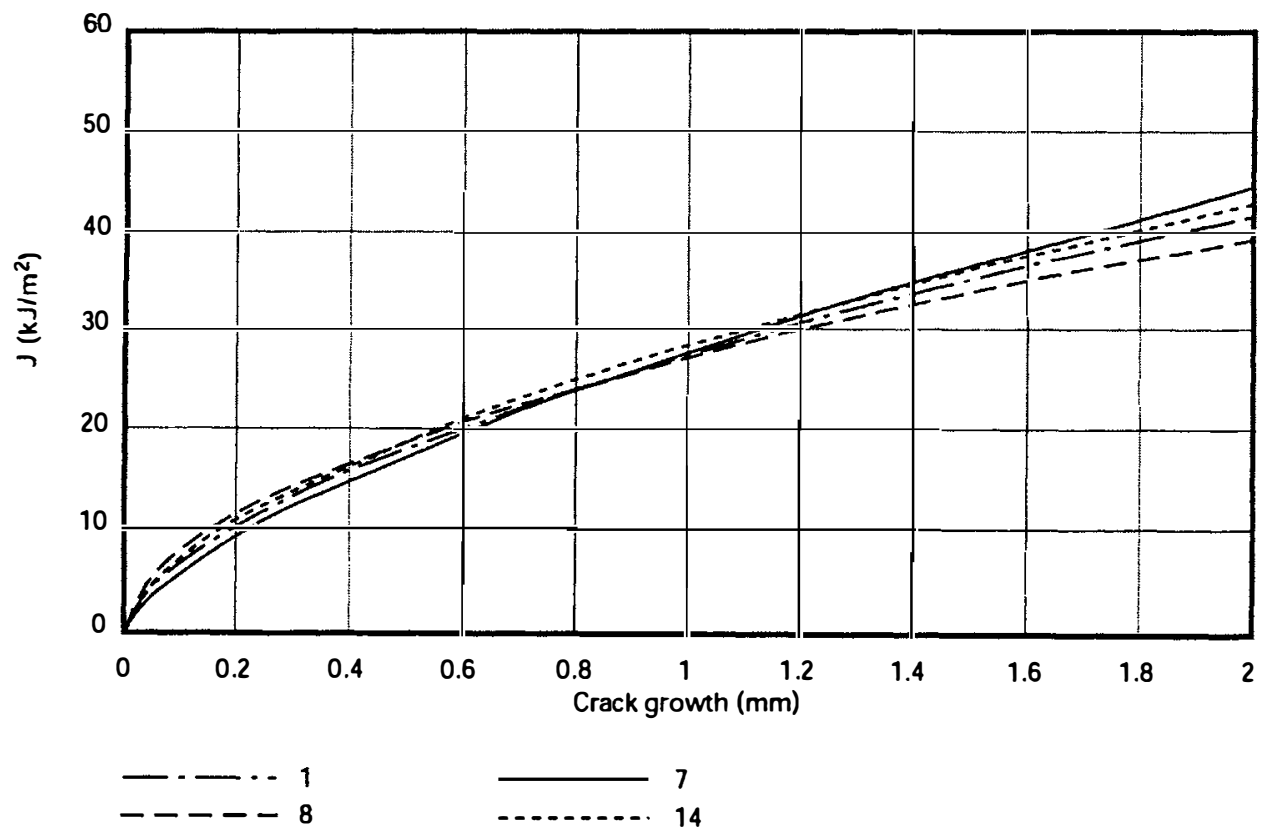

Fig.6 Compilation of J R-curves for sidegrooved SENB specimens of a polyamide blend, measured at four laboratories. 
Excellent comparative data were obtained between four laboratories after carrying out te its on SENB specimens extracted from $16 \mathrm{~mm}$ thick discs of a polyamide blend (Fig. 6). Table 4 summarises the data generated by each laboratory. In this case, the mean value of $\mathrm{J}_{0.2}$ is $10.6 \mathrm{~kJ} / \mathrm{m}^{2}$.

Table 4 Compilation of J R-Curve Data for a polyamide blend (sidegrooved SENB specimens)

\begin{tabular}{|c|l|c|c|c|}
\hline Organisation & Notch sharpening method & $\mathrm{J}_{0.2}\left(\mathrm{~kJ} / \mathrm{m}^{2}\right)$ & \multicolumn{2}{|c|}{ Curve-fitting parameters } \\
\hline & & & A & N \\
\hline 1 & Tapped scalpel blade & 10.54 & 27.64 & 0.599 \\
\hline 7 & $\begin{array}{l}\text { Fly wheel cutter and razor } \\
\text { tap }\end{array}$ & 9.43 & 28.01 & 0.676 \\
\hline 8 & Fly cutter & 11.50 & 27.35 & 0.538 \\
\hline 14 & Sliding razor blade & 11.00 & 28.60 & 0.592 \\
\hline
\end{tabular}

\subsection{Plastics where additional crack face features complicate interpretation}

In some instances, e.g. with some grades of HDPE, abnormally large crack growth values were reported by a number of laboratories.

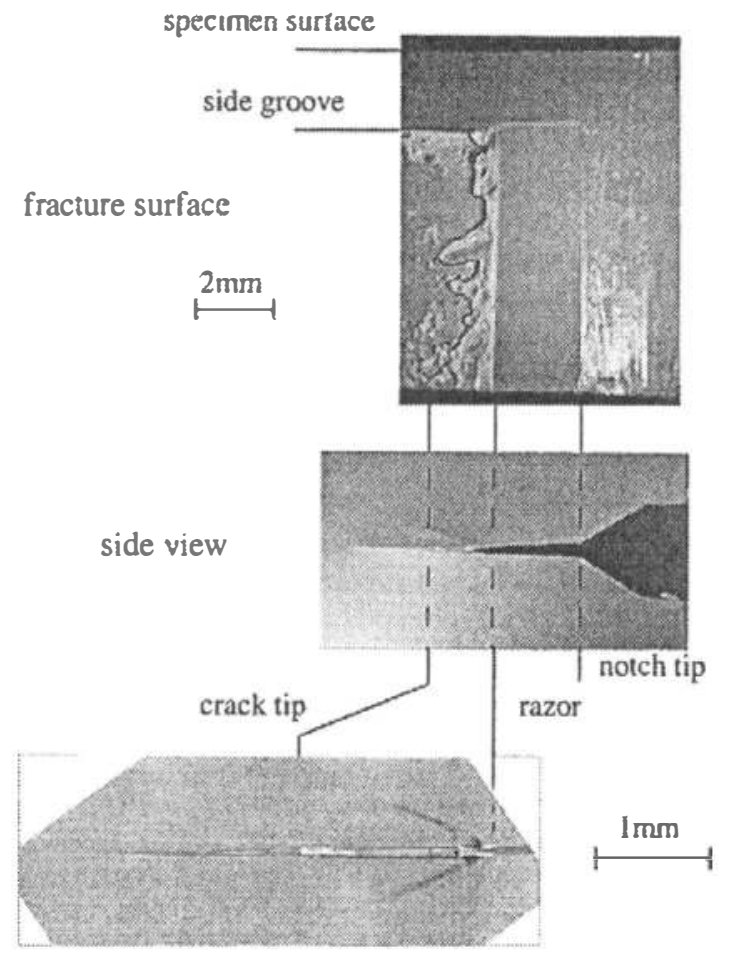

Fig.7 Fracture surface and side view section taken perpendicular to the direction of crack propagation in a CT-specimen of HDPE tested at $-20^{\circ} \mathrm{C}$, with $\mathrm{J}=30 \mathrm{~kJ} / \mathrm{m}^{2}, \Delta \mathrm{a}=1 \mathrm{~mm}$ 
If a comparison is made between the fracture surface and a section taken perpendicular to the fracture from a cracked but unbroken testpiece, it becomes clear that the crack front (or what is thought to be the crack front) is very wavy in this material. Fig. 7 compares the fracture surface itself and a side view from a section cut perpendicular to the fracture surface at the midplane of the specimen before it was broken open. While there is good correspondence between the crack tip on the fracture surface and the side view, precise definition of the final crack length is not a simple task. This situation is further complicated if the notch propagates by multiple cracking, as shown in Fig. 8 for polypropylene.

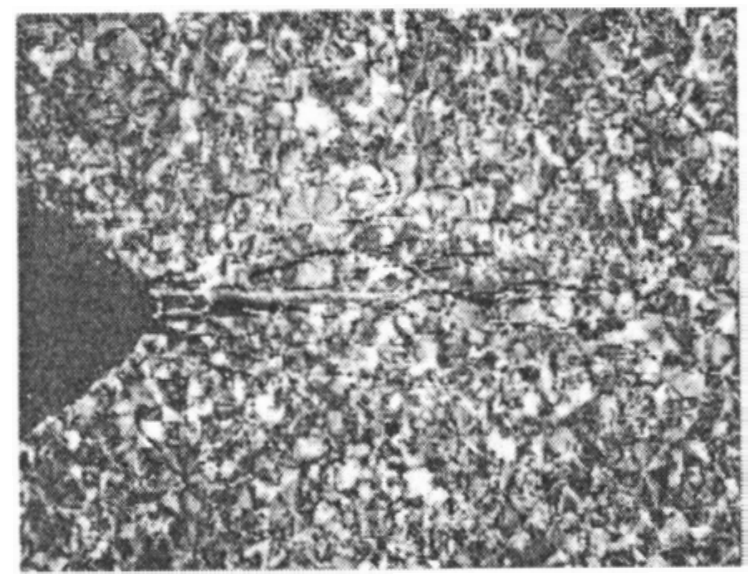

Fig.8 Side view of a section (taken under polarised light) from a specimen cut perpendicular to the direction of crack growth which illustrates the development of multiple cracking in polypropylene

\subsection{Thermoplastics exhibiting fine-scale fracture face features}

Provided that experimental conditions are carefully controlled and the requirements of the test protocol are followed, it is possible to obtain consistent fracture toughness data for polymers which exhibit fine multiple cracks ahead of the primary crack tip.

For instance, Fig. 9 shows data obtained by three laboratories on specimens exracted from a $12.5 \mathrm{~mm}$ thick random ethylene/propylene copolymer which have been treated as one homogeneous set of data. The results regress to a power law fit:

$$
J=16.27 \Delta a^{0.54}
$$

In this case, $\mathrm{J}_{0.2}=6.8 \mathrm{~kJ} / \mathrm{m}^{2}$. 


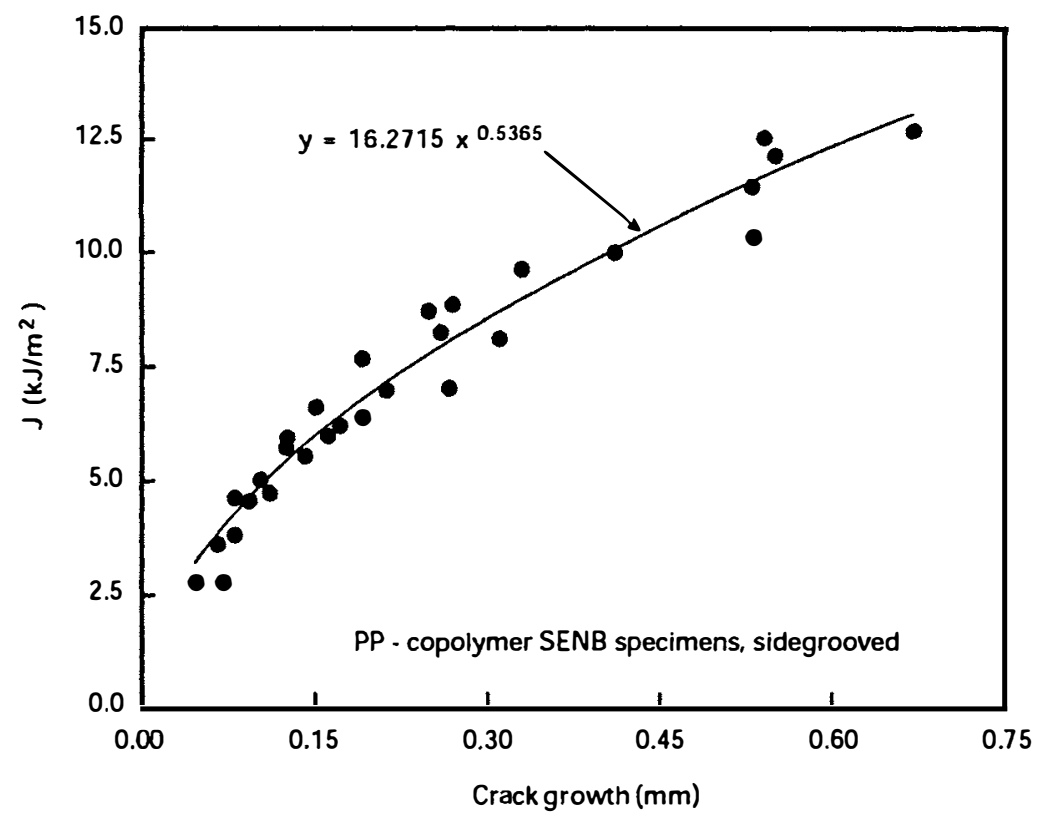

Fig.9 Power law fit to data generated for a random ethylene/propylene copolymer (sidegrooved SENB specimens; data obtained from three laboratories)

Good correlation was obtained between the crack opening observed on sections and measurements on the fracture faces themselves. Examination indicated that partial fracture, i.e. cracking and voiding, also occurs ahead of the crack tip in this type of semi-crystalline polymer as shown in Fig. 8 for polypropylene. In many instances, the microstructural inhomogeneity present in such semi-crystalline polymers can make crack tip measurement insufficiently precise and hence two other options should be considered:

(1) a full J R-curve may be a more effective way of describing the fracture resistance of this type of thermoplastic;

(2) it may be feasible to apply a blunting line approach to polymers which deform in this manner.

Data determined in one laboratory (Fig. 10) illustrate that a blunting line can be appropriate. 


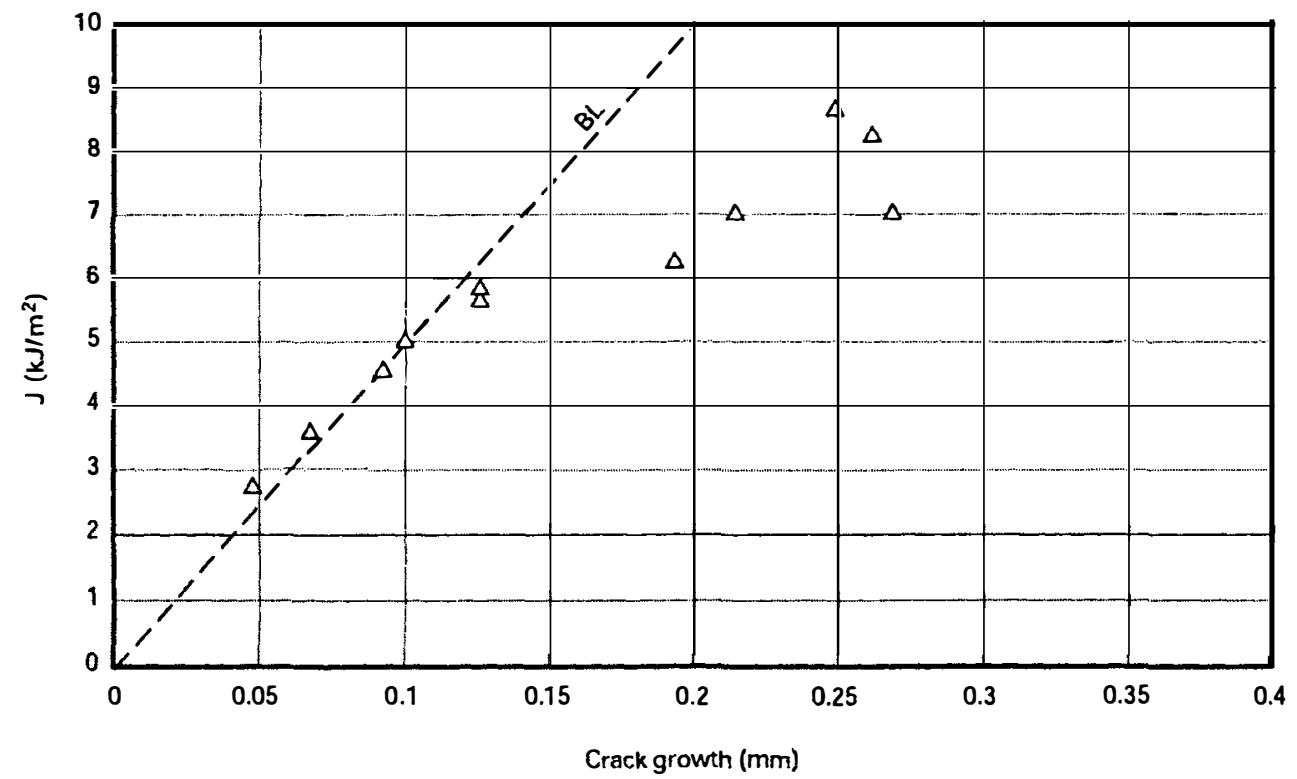

Fig.10 J - $\Delta$ a data for an ethylene/propylene copolymer illustrating potential crack tip blunting in the early stages of deformation at $23^{\circ} \mathrm{C}$ and a loading rate of $1 \mathrm{~mm} / \mathrm{min}$, using SENB specimens.

It should be noted however that four other laboratories were unsuccessful in characterising this material by a J R-curve approach, as they were unable to detect any significant crack growth over a range of test conditions. Even in the three laboratories that did generate valid experimental data, the maximum measured crack growth was only $0.67 \mathrm{~mm}$, although these figures were correlated by comparing fracture face measurements and those determined via sectioning.

Similar work on polypropylene indicated that crack propagation was strongly influenced by its spherulitic structure which resulted in partial splitting of the crack front (Fig.8).

Overall, experimental evidence indicates that the use of a static $\mathrm{J}$ - crack growth resistance curve approach to characterise thermoplastics which exhibit this form of multiple cracking (with a spacing of 0.1 to $0.3 \mathrm{~mm}$ ) on the fracture face, is not readily applicable.

\section{CONCLUSIONS}

This paper summarises work undertaken by laboratories across Europe (plus one laboratory in the USA) to assess the applicability of a J-testing procedure developed by ESIS to determine the crack growth resistance behaviour of plastics.

The major conclusions are:

1. The elastic-plastic fracture mechanics parameter $\mathrm{J}$ can be used successfully to characterise the fracture toughness of ductile thermoplastics at slow speeds by employing a multiple 
specimen approach to determine a complete J-crack growth resistance curve.

2. The controlling factor in obtaining consistent results is accurate measurement of the a:nount of crack growth which occurs during the J-test. It was found that two inter-related factors have a major effect on crack length measurements after testing:

- the method used to break-open the testpiece;

- interpretation of features on the fracture face arising as a result of the various deformation mechanisms which occur in different polymers.

3. A pseudo-initiation parameter - $\mathrm{J}_{0.2}$ (i.e. $\mathrm{J}$ determined at $0.2 \mathrm{~mm}$ of total crack growth) - can be determined to characterise crack instability

4. A J R-curve approach is no longer applicable in cases where:

- the fracture face exhibits fine-scale features (typically of the order of 0.1 to $0.3 \mathrm{~mm}$ ) which result in apparent uneven crack growth and the presence of multiple cracking ahead of the principal crack tip;

- the material is very inhomogeneous as a result of a coarse grained structure;

- the material is extremely tough and yielding occurs at the crack tip rather than actual crack propagation.

\section{RECOMMENDATIONS}

The testing protocol should be adopted as "best practice" for determining the J-crack growth resistance behaviour of thermoplastics, until such time as ISO or CEN standards become available.

\section{REFERENCES}

1. Rice, J. R. (1968). Trans ASME, Journal of Applied Mechanics, Vol. 35, June pp. 379-386.

2. Begley, J. A. and Landes, J. D. (1972). The J Integral as a fracture criterion, In: ASTM STP 514, Fracture Toughness, Proc. 1971 National Symposium on Fracture Mechanics, Urbana, Illinois, USA, 31 Aug - 2 Sept 1971, Part II, published by ASTM, Philadelphia, USA, pp 1-20

3. .Landes, J.D. and Zhou, Z. (1993). Application of load separation and normalisation methods for polycarbonate materials, Int. Joumal of Fracture, Vol. 63, No. 4, 15 October, pp 383-393

4. Landes, J. D. and Begley, J. A. (1974). Test results from J-Integral studies: An attem tht to establish a $\mathrm{J}_{\mathrm{lc}}$ testing procedure, In: ASTM STP 560 , Fracture Analysis, Proc. 1973 National Symposium on Fracture Mechanics, Univ. of Maryland, Maryland, USA, $2,-29$ Aug 1973, Part II, published by ASTM, Philadelphia, USA, pp 170-186

5. Hashemi, S. and Williams, J.G., (1986). Fracture toughness study on low density and linear low density polyethylenes, Polymer, Vol. 27, No. 3, March, pp 387-392 


\section{ACKNOWLEDGEMENTS}

The authors wish to thank all the members of the ESIS Technical Committee on Polymers and Composites who have contributed their data and expertise during the development and evaluation of the testing protocol. Thanks are due to BASF, BP Chemicals, Du Pont, ICI, Pipeline Developments and Solvay for the provision of materials at various stages of this project, without which this study could not have been undertaken. GEH wishes to acknowledge the funding provided by the UK Government Department of Trade and Industry and the Industrial Members of TWI. 


\section{APPENDIX}

A TESTING PROTOCOL FOR CONDUCTING J-CRACK GROWTH RESISTANCE CURVE TESTS ON PLASTICS

June 2000

Prepared on behalf of the

ESIS Technical Committee on

Polymers and Composites 


\section{NOMENCLATURE}

\section{Specimen dimensions}

$a_{0} \quad$ initial crack length (i.e. machined notch plus razor sharpened tip)

$a_{f} \quad$ final crack length

$\mathrm{b}_{\mathrm{o}}$ original uncracked ligament $\left(\mathrm{W}-\mathrm{a}_{\mathrm{o}}\right)$

B specimen thickness

$\mathrm{B}_{\mathrm{N}} \quad$ net thickness of sidegrooved specimens

$S \quad$ span of single edge notch bend specimen

W specimen width

\section{Material Properties}

E axial modulus of elasticity (Young's modulus)

$\sigma_{\mathrm{f}} \quad$ flow stress

$\sigma_{u} \quad$ nupture strength

$\sigma_{y} \quad$ yield strength

\section{Fracture Parameters and Related Quantities}

$\Delta$ a crack growth

$\Delta \mathrm{a}_{\max }$ validity limit for J-controlled crack growth

P load

v displacement

C elastic compliance $(\Delta \mathrm{v} / \Delta \mathrm{P})$

$\mathrm{J}_{\mathrm{o}} \quad$ fracture resistance not allowing for crack growth

$\mathrm{J}_{\mathrm{c}} \quad$ fracture resistance at crack initiation

$\mathrm{J}_{\mathrm{BL}} \quad$ fracture resistance where the blunting line intersects with the J- $\Delta$ a curve

$\mathrm{J}_{0.2}$ fracture resistance at $0.2 \mathrm{~mm}$ of total crack growth including crack tip blunting

$\mathrm{J}_{\max } \quad$ validity limit for $\mathrm{J}$

$\mathrm{J}_{\mathrm{Ic}} \quad$ critical value of $\mathrm{J}$, at the onset of stable crack extension

$\eta \quad$ calibration factor

U the area under the load versus load-point displacement record up to the line of constant displacement corresponding to the termination of the test 


\section{A TESTING PROTOCOL FOR CONDUCTING J-CRACK GROWTH RESISTANCE CURVE TESTS ON PLASTICS}

June 2000

This protocol has been prepared by Dr. Geoff Hale, TWI Ltd and incorporates information gained from a series of round-robin exercises conducted by the ESIS Technical Committee on Polymers and Composites. Valuable comments and suggestions have also been provided by the ASTM task group who were responsible for the preparation of ASTM D6068-96 [1]. Any comments and enquiries should be addressed to Geoff Hale at TWI Ltd.

\section{INTRODUCTION}

J-fracture toughness testing of ductile metallic materials is currently covered by ASTM E1820-99 [2] and an ESIS procedure, ESIS P1-92 [3]. These documents and their predecessors were used as the basis for developing an equivalent testing procedure for plastic materials.

For polymers, stable crack growth is either measured using several specimens loaded to different displacements (multiple specimen technique) or it may be estimated from the elastic compliance measured during unloading-loading cycles using a single specimen (single specimen technique). The text of this protocol is concerned with a multiple specimen approach. It provides information on the conduct of the tests, those thermoplastics for which the protocol works well and those where care is needed to avoid problems.

\section{SPECIMEN CONFIGURATION AND SIZE}

Compact tension (CT) or three point bend (SENB) specimens may be used (Fig. 1). As in the case of the LEFM standard [4], the specimen thickness is usually taken as the maximum available, i.e. the sheet thickness B. If the material surface is uneven, it may be skimmed, but as little material as possible should be removed so that the greatest possible sheet thickness is maintained. The width, $\mathrm{W}$, is generally equal to twice the specimen thickness, i.e. $\mathrm{W}=2 \mathrm{~B}$, and this configuration maximises the opportunity to obtain plane strain conditions at the crack tip. This is the approach used conventionally for metals and it has been employed successfully when carrying out LEFM tests on plastics. 

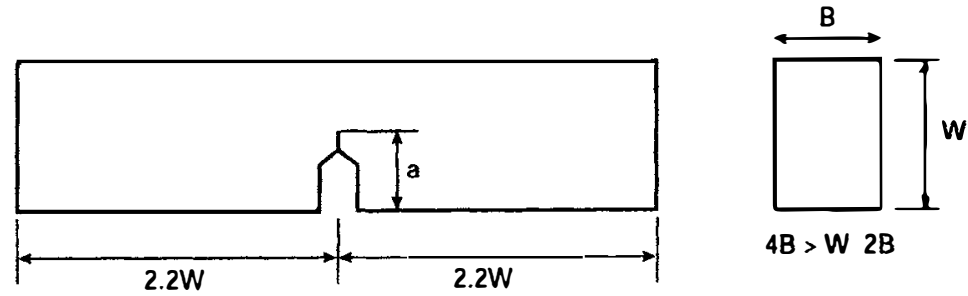

$4 B>W 2 B$

(a)

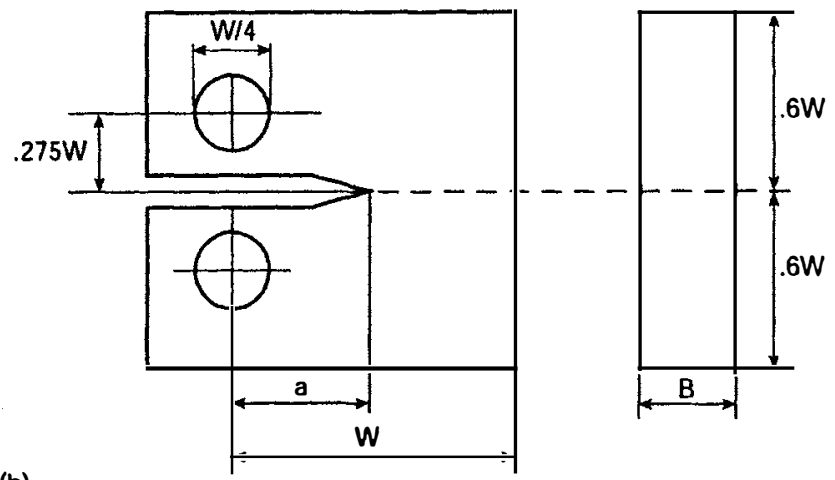

(b)

Fig. 1 Specimen configurations

(a) Three point bend specimen (SENB)

(b) Compact tension configuration (CT)

\section{NOTCHING}

The crack tip should be as sharp as possible and it is suggested that specimens are precracked by sliding or tapping a razor blade into the root of a machined notch, which is ideally produced using either a broach or a single point flycutter so that the tip radius $\rho \leq 20 \mu \mathrm{m}$. Altematively, fatigue precracking can be employed. (Note, to avoid hysteretic heating in polymers, it may be necessary to fatigue at very low frequencies, $<4 \mathrm{~Hz}$ in some instances). Pressing the razor blade into the crack tip is not permissible.

The length of the precrack $\left(a_{0}\right)$ for both SENB and CT specimen geometries should satisfy the requirement:

\section{$0.55 \leq \mathrm{a}_{0} \mathrm{~W} \leq 0.65$}

Furthermore, the initial pre-crack lengths should not vary by more than $0.05 \mathrm{~W}$.

\section{SIDEGROOVING}

Specimens must be sidegrooved whenever possible to promote growth of a straight ductile crack front so that measurement of total crack growth at the end of the test is simpler. The sidegrooves should be equal in depth and have an included angle of $45^{\circ} \pm 5^{\circ}$ with a root radius of $0.25 \pm$ 
$0.05 \mathrm{~mm}$. The total reduction in thickness shall not exceed $0.20 \mathrm{~B}$. Past experience suggests that $10 \%$ sidegrooving on each face with a cutter having an included angle of not less than $45^{\circ}$ and a minimum root radius of $0.25 \mathrm{~mm}$ is likely to be sufficient. (If the side-grooves are too sharp, then crack growth initiates from the root of the sidegrooves and not from the centre of the testpiece.) If plane-sided specimens are used, the difference between the mean crack growth and any of the measurement points should be less than $30 \%$. If this figure of $30 \%$ is exceeded, then sidegrooved specimens must be employed.

\section{TEST CONDITIONS}

Since plastics are viscoelastic materials, it is essential that the temperature and loading rate are recorded. In the first instance, to aid comparison, it is recommended that all tests are conducted at a temperature of $23^{\circ} \mathrm{C}$ and a loading rate of $1 \mathrm{~mm} / \mathrm{min}$. These conditions are known to yield consistent crack growth resistance curves for those thermoplastics which exhibit stable and welldefined crack growth. If a material exhibits unstable crack growth during the test (i.e. short arrested brittle cracks, sometimes described as 'pop-ins'), then either a slower loading rate (probably $0.1 \mathrm{~mm} / \mathrm{min}$ ) or a higher test temperature must be used. Further advice is given below.

\section{MEASUREMENT OF DISPLACEMENT}

In order to calculate $\mathrm{J}$, the displacement must be measured on the load line.

For a CT specimen, this can be achieved by an extensometer (i.e. a LVDT or a clip gauge) placed in the notch on the load line, or the displacement can be calculated from the crosshead displacement rate of the test machine corrected by the compliance of the fixtures and indentation.

For a SENB specimen, it is not as easy to measure the real displacement at the load line. Corrections should be made to account for deformation due to roller indentation, pin penetration etc. in a similar manner to the procedure described in the LEFM standard [4]. Altematively, a comparator bar may be used. Further details of each approach can be found in Annex A.

\section{LOADING RIGS}

For SENB specimens, a rig with moving rollers of sufficiently large diameter to minimise plastic indentation is recommended (Fig. 2). For the CT geometry, loading is via pins through the holes (Fig. 1). 

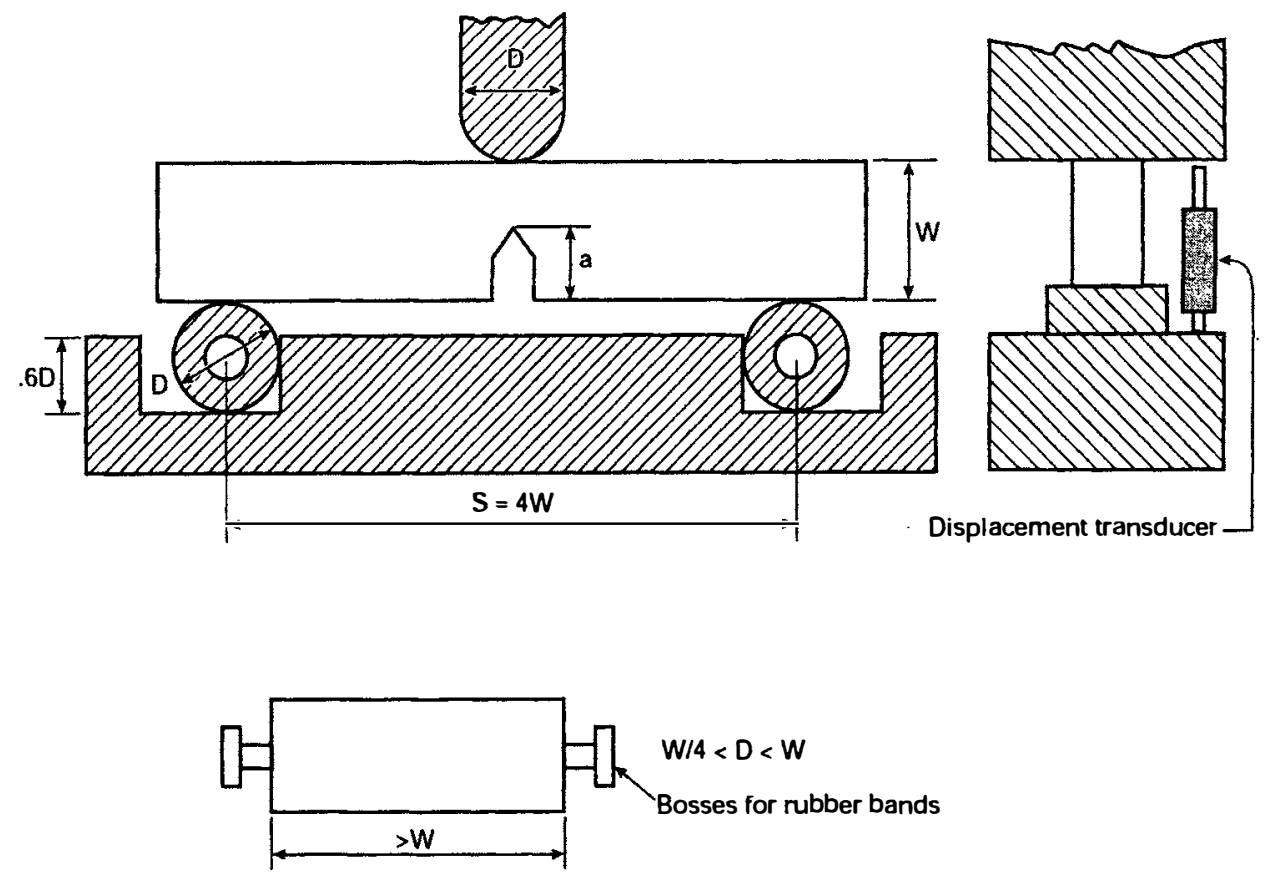

Fig. 2 Bending rig

\section{TEST PROCEDURE}

A series of specimens are loaded to different displacements and the amount of crack extension which occurs during testing is determined.

With the first specimen, it is good practice to just exceed maximum load so that subsequent displacement levels can be estimated more accurately using this initial record. To control crack growth beyond maximum load, displacement or clip gauge control should be employed.

Break open the specimen and determine the amount of crack growth following the procedures described in Section 9.

Evaluate $\mathrm{J}$ using the procedure given in Section 11.

The test procedure is repeated for at least six further specimens choosing displacements such that the crack growth satisfies the validity requirements given in Section 12.

\section{CRACK LENGTH MEASUREMENT}

The final crack growth resistance curve is strongly influenced by the accuracy of the crack growth measurements made once testing is complete. These measurements must be carried out directly on the fracture face, but certain precautions are necessary to minimise the risk of incorrect 
measurements. While the initial crack length $\left(a_{0}\right)$ can be determined relatively easily, greater care is required when measuring the final crack length.

Measurement of the final crack front from the fracture face is clearly a subjective matter and is therefore prone to error. Furthermore, there has been some evidence that, in certain plastics, the 'breaking-open' operation may cause additional crack growth. Therefore, while direct measurement from the fracture face is the primary approach adopted, this must be supplemented by sectioning at least two specimens through the centre. One specimen should exhibit a small amount of crack growth, e.g. around 0.1 to $0.2 \mathrm{~mm}$. For the second specimen, crack growth should be measured at or close to maximum load. Comparisons of the crack growth measured on the sectioned face and that of an equivalent testpiece broken open by one of the methods described in Annex B can be made. With this approach, it is possible to confirm which feature on the racture face corresponds to the actual crack growth that occurred in the test itself. Once established, all subsequent measurements can be made on the fracture face up to the defined feature.

Information on crack length measurement directly from the fracture face is given in Annex B together with advice on sectioning.

The initial and final crack lengths ( $a_{0}$ and $a_{f}$ respectively) are measured using either a travelling microscope or a high power optical microscope.

There is generally no difficulty measuring the initial crack length $\left(a_{0}\right)$ at the tip of the razorsharpened region. Three equidistant measurements are used as shown in Fig. 3. The initial crack length $\left(a_{0}\right)$ is the average of the three measured values.

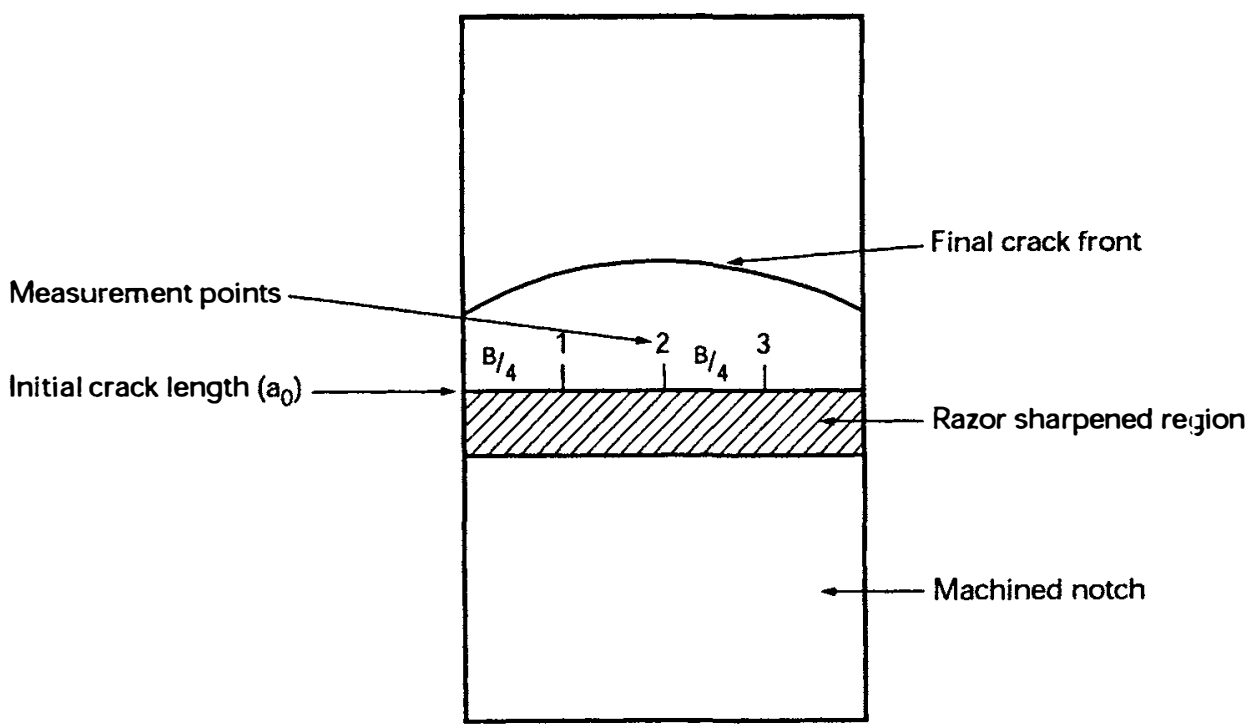

Fig. 3 Measurement of initial crack length $\left(a_{0}\right)$ 


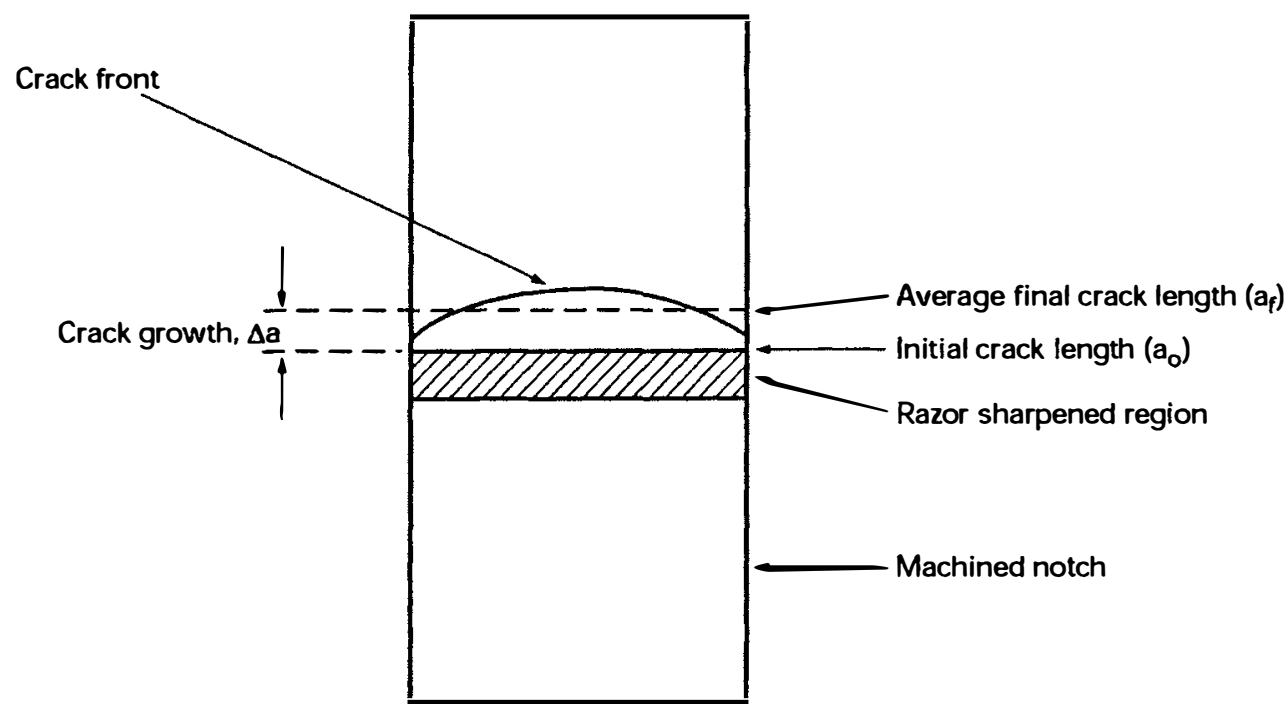

Fig. 4 Measurement of final crack length $\left(a_{f}\right)$

The final crack length $\left(a_{f}\right)$ is determined by establishing a 'subjective' average crack growth (Fig. 4). This is obtained by positioning the microscope cross-hair at the centre of the curved crack front. (Note: This is less rigorous than a true average, but more practical when a large number of specimens are to be tested. The previous protocol used a nine-point average as adopted by the metals community).

Illumination of the fracture face can cause difficulties in interpreting the limit of ductile crack growth. One suggestion is to light the specimen from the side but other options may be explored.

\section{RESPONSE OF DIFFERENT THERMOPLASTICS}

The crack growth behaviour exhibited by thermoplastics can be described as:-

a. Easy to characterise. Distinct markings visible on the fracture face which correlate with the measurements made on sections cut at $90^{\circ}$ to the fracture face. Typical examples include: rubber-toughened PMMA, ABS, polyamide blends etc.

b. Additional features such as half-moons may appear on the fracture face (see Fig.B1 in Annex B). These can be mistaken for actual crack growth unless a section is taken as described above. Examples include high density polyethylenes.

c. Crack growth obscured by an uneven and rough fracture face. This often occurs in thermoplastics which exhibit crazing at the crack ip, e.g. polypropylenes. This may result in thin slivers of material overlaying the main fracture face. Once again, sectioning perpendicular to the fracture provides additional confirmation of the region of crack growth. 
d. It is recognised that the fracture faces of some semi-crystalline thermoplastics which exhibit small-scale inhomogeneous structures (typically in the range of 0.1 to $19.3 \mathrm{~mm}$ ), such as polypropylenes and some polyethylenes, are extremely difficult to characterise because of uneven crack growth and the presence of multiple cracking ahead of the principal crack tip. In these materials, it can be difficult to decide if crack growth has taken place or not. Alternative approaches should be employed, if possible, to measure the fracture toughness of the material, e.g. LEFM testing at lower temperature.

If sectioning perpendicular to the fracture does not provide a positive answer, then characterisation of the material's resistance to stable crack growth is not likely to be successful.

\section{ANALYSIS PROCEDURE}

\subsection{Fracture Resistance J}

There are several formulae available for determining the fracture resistance J. The formula given here is considered the most appropriate for multiple specimen testing. It has the advantage of avoiding the need to partition the area $U$ under the load displacement record into elastic and plastic components as used in the ASTM methods. Furthermore, over the allowable a/W' range, the formula is virtually identical to those which partition $U$.

Calculate $\mathrm{J}_{\mathrm{o}}$ for each specimen using the relationship

$$
J_{o}=\frac{\eta U}{B_{N}\left(W \cdot a_{o}\right)}
$$

where

$\mathbf{J}_{\mathrm{o}} \quad$ fracture resistance not allowing for crack growth

$\eta \quad 2+0.522\left(1-\mathrm{a}_{0} / \mathrm{W}\right)$ for compact tension specimens,

2 for single edge notch bend specimens

$\mathrm{B}_{\mathrm{N}} \quad$ net thickness of sidegrooved specimens

$\mathrm{U}$ is the area under the load versus load-point displacement record up to the line of constant displacement corresponding to the termination of the test (Fig. 5).

If plane-sided specimens are used replace $B_{N}$ with $B$ in the above formula. 


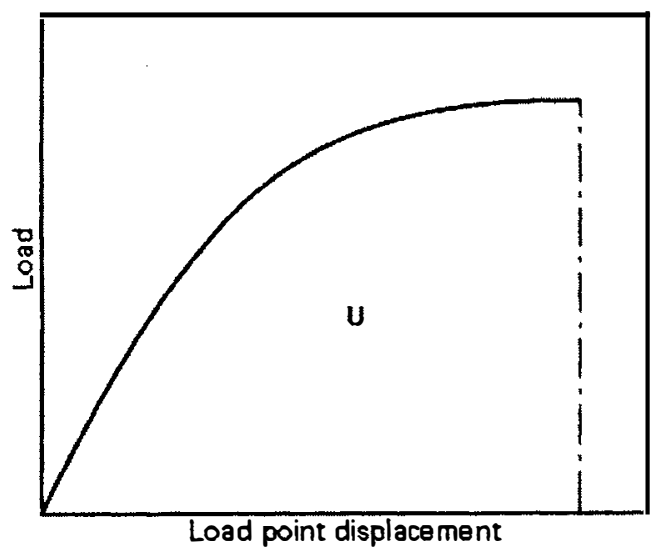

Fig. 5 Definition of absorbed energy U

\subsection{Crack Growth, $\Delta a$}

$\Delta \mathrm{a}$ is the difference between the final crack length $\left(a_{f}\right)$ and the initial crack length $\left(a_{0}\right)$ measured from the fracture faces of each specimen.

\section{CONSTRUCTION OF VALID CRACK GROWTH RESISTANCE CURVES}

Using the data determined in Section 11, a plot of fracture resistance against crack growth is constructed.

Since small amounts of crack growth are difficult to measure and hence are subject to error, a $0.05 \mathrm{~mm}$ exclusion line parallel to the $\mathrm{J}$-axis is used (Fig. 6). Only data beyond this exclusion line are used to determine the best fit curve.

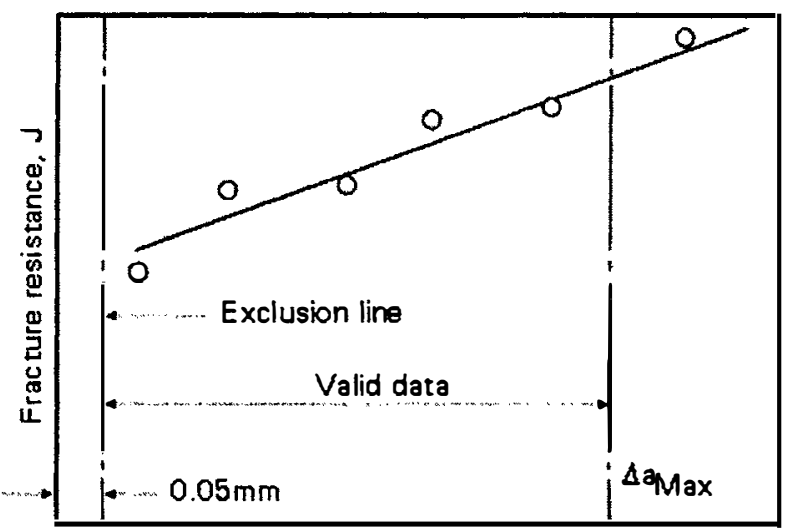

Crack growth, $\Delta a$

Fig. 6 Data points to be used for curve fitting 
Determine the magnitude of the parameter, $\Delta \mathrm{a}_{\max }$ where:

$\Delta \mathrm{a}_{\max }=0.1\left(\mathrm{~W}-\mathrm{a}_{0}\right)$

where $\left(\mathrm{W}-\mathrm{a}_{0}\right)$ is the initial uncracked ligament.

Some of the earlier work on the use of J-fracture toughness for polymers indicated that a $6 \%$ limit on uncracked ligament size was too restrictive for plastics $[5,6]$ and therefore a higher value of $10 \%$ has been adopted. Above this limit (i.e. $\Delta \mathrm{a}_{\max }$ ), $\mathrm{J}$ may not necessarily be a valid characterising parameter.

There are insufficient data available at present to establish whether the limit on uncracked ligament size $\left(\Delta \mathrm{a}_{\mathrm{max}}\right)$ should be greater than $10 \%$.

A second exclusion line parallel to the J-axis is drawn through $\Delta \mathrm{a}_{\max }$ (Fig. 6).

To ensure that the data points are evenly spaced, the interval between the $0.05 \mathrm{~mm}$ and $\Delta \mathrm{a}_{\max }$ exclusion lines (see Fig.7) is divided into four equal sections. At least one $(\mathrm{J}, \Delta \mathrm{a})$ data point is required in each quadrant. However, since there is an interest in determining some form of fracture initiation parameter, a further two specimens are required in the first section so that the position of the J- $\Delta \mathrm{a}$ curve, in the vicinity of $\Delta \mathrm{a}=0.2 \mathrm{~mm}$, is more clearly defined. At least seven specimens must fall between the 0.05 and $\Delta \mathrm{a}_{\max }$ exclusion lines for a J- $\Delta$ a curve to be valid

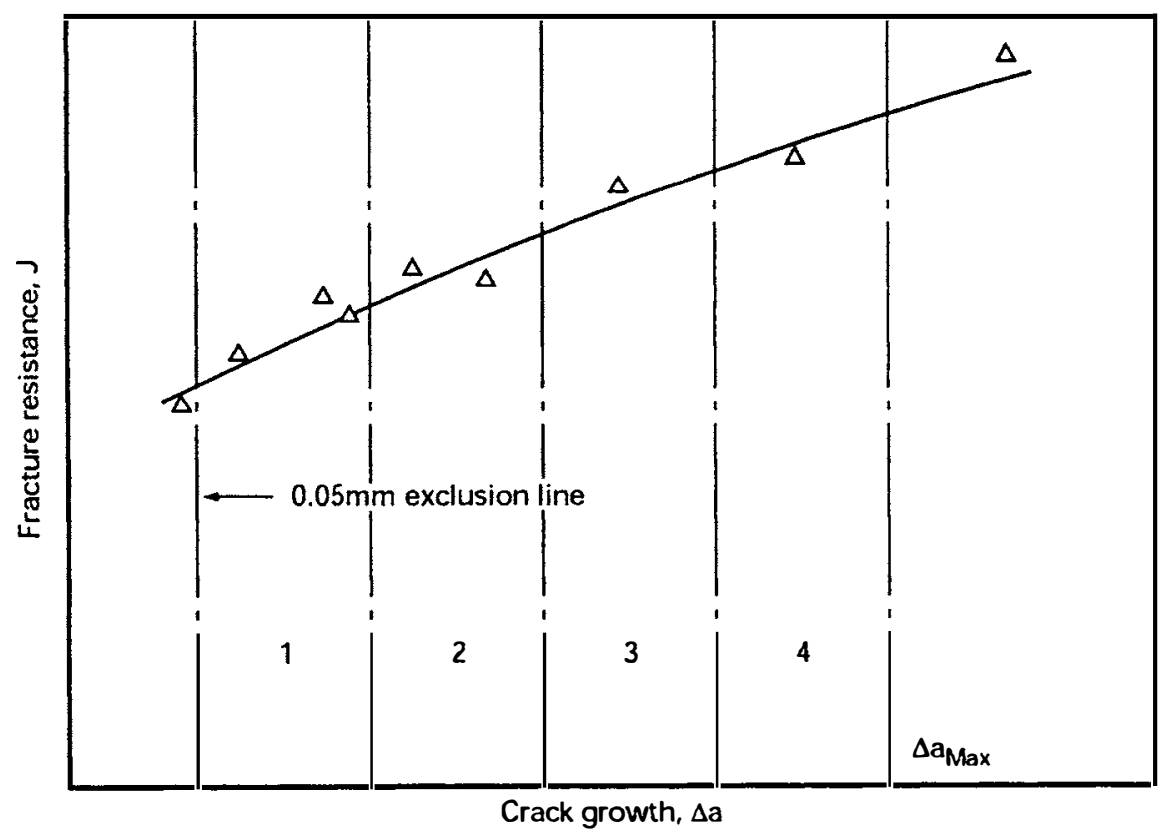

Fig. 7 Data spacing requirement 
Users should state in their report whether the requirements outlined above can be satisfied or not. If not, they should still continue with the curve fitting routine described below but they should make it clear in their report where they failed to meet the validity and spacing requirements.

A best fit curve may now be plotted through all the data points falling between the $0.05 \mathrm{~mm}$ offset exclusion line and the $\Delta \mathrm{a}_{\max }$ exclusion line, using a simple power law of the form:

$$
J=A \Delta \mathbf{a}^{\mathrm{N}}
$$

where $\mathrm{A}$ and $\mathrm{N}$ are constants.

\section{and $\mathrm{N} \leq 1$}

If $\mathrm{N}>1$, then the validity of the data should be questioned and it must be rechecked.

If the maximum amount of crack growth achieved in the test is less than $\Delta \mathrm{a}_{\max }$, then all the data points between the $0.05 \mathrm{~mm}$ exclusion line and this value should be used for the curve-fitting routine. However, in most instances, the crack growth measured in a specimen taken beyond the maximum load position on the load-displacement trace will be greater than $\Delta \mathrm{a}_{\max }$ and, as noted earlier, this procedure should be employed with the first testpiece to obtain a reference point.

In the metals field, the concept of a J-controlled crack growth resistance curve is widely used and certain validity limits are defined to establish the region within which a J-controlled crack growth process occurs. There is insufficient experimental evidence available to indicate if the same limits can be applied to plastics and hence the concept of a region of J-controlled crack growth has not been pursued at this point in time.

\section{DETERMINATION OF INITIATIONTOUGHNESS, JC}

The initiation toughness is defined as the lower value of a $\mathrm{J}_{0.2}$ parameter (i.e. J measured at $0.2 \mathrm{~mm}$ of total crack growth (including crack tip blunting\}) or a $\mathrm{J}_{\mathrm{BL}}$ value (specified as the intersection of the blunting line with the J- $\Delta$ a curve) as shown in Fig. 8.
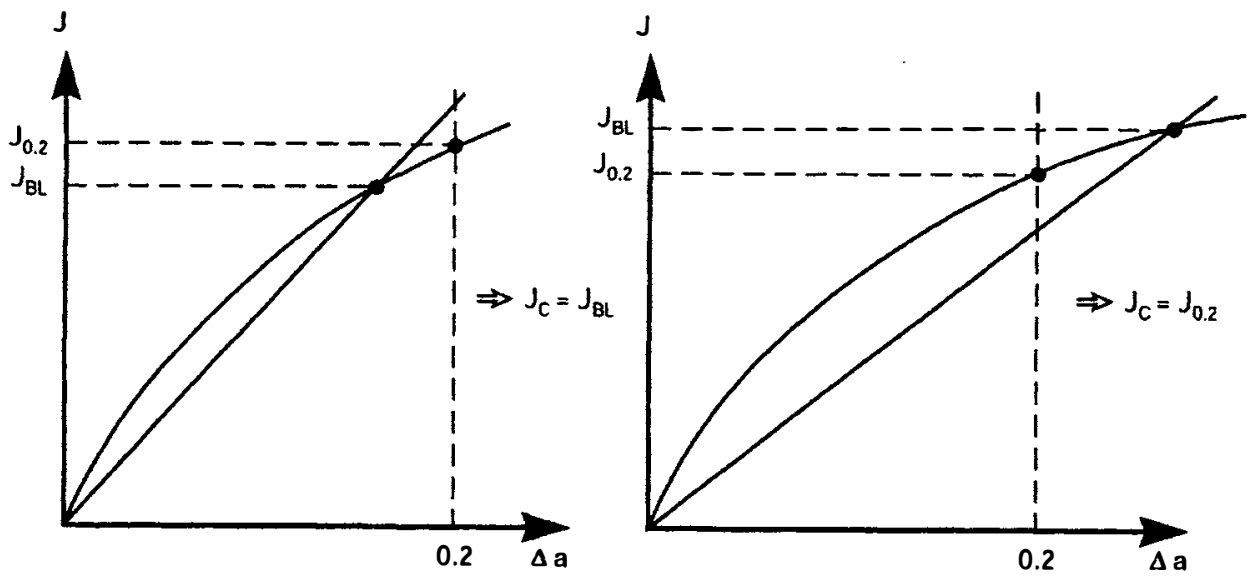

Fig. 8 Definition of initiation parameter $\left(\mathrm{J}_{\mathrm{c}}\right)$ 
$\mathrm{J}_{0.2}$ is considered to be valid if:

(i) at least one $\mathrm{J}-\Delta$ a point falls between 0.2 and $0.4 \mathrm{~mm}$ of crack growth

(ii) $\quad \mathrm{J}_{0.2} \leq \mathrm{J}_{\max }$

where $\mathrm{J}_{\max }$ is the smaller of $\left(\mathrm{W}-\mathrm{a}_{0}\right) \sigma_{\mathrm{y}} / 20$ or $\mathrm{B} \sigma_{\mathrm{y}} / 20$

Similarly, $\mathrm{J}_{\mathrm{BL}}$ must also be less than $\mathrm{J}_{\max }$.

In this protocol, the flow stress, $\sigma_{\mathrm{f}}\left[=\left(\sigma_{\mathrm{y}}+\sigma_{\mathrm{u}}\right) / 2\right]$, used in the metals field is replaced by the conventional polymer physics definition of uniaxial yield strength, i.e. the first attainment of the maximum load. To minimise the risk of brittle fracture in tensile tests, it is often necessary to polish the edge of tensile specimens. The yield strength should be measured at $1 \mathrm{~mm} / \mathrm{min}$ (or at a slower displacement rate as defined in Section 5 above).

If any of the specimens exhibit brittle cleavage fracture before maximum load, under the test conditions specified, i.e. temperature and loading rate, this must be stated in the report.

\section{REPORTING}

An outline reporting form is attached (see Annex C). This should be completed as fully as possible. A copy of the final J- $\Delta$ a best fit curve should be included. All experimental points and exclusion lines should be shown on this plot. Sketches showing the variation in precrack length $\left(a_{0}\right)$ and final crack length $\left(a_{f}\right)$ would be useful. Photographs from some of the fracture faces should be attached if possible.

\section{REFERENCES}

1. ASTM D6068-96. Test method for determining J-R curves of plastic materials

2. ASTM E1820-99. Standard test method for measurement of fracture toughness

3. ESIS P1-92. ESIS recommendations for determining the fracture resistance of ductile materials, European Structural Integrity Society, January 1992.

4. ISO 13586. Determination of fracture toughness $\left(G_{\mathrm{lc}}\right.$ and $\left.\mathrm{K}_{\mathrm{lc}}\right)$ - Linear Elastic Fracture Mechanics (LEFM) approach, 2000

5. Hashemi, S. and Williams, J. G: (1986). The effects of specimen configuration and notch tip radius on the fracture toughness of polymers using $\mathrm{J}_{\mathrm{c}}$, Plastics and Rubber Processing and Applications, Vol. 6, No. 4, pp. 363-375.

6. Chung, W. N. and Williams, J. G: (1991). Determination of $\mathrm{J}_{\mathrm{lc}}$ of polymers using the single specimen method, In: ASTM STP 1114, Elastic-Plastic Fracture Test Methods: The User's Experience, Proc. 2nd Symposium on User experience with elastic plastic fracture test methods, Lake Buena Vista, Florida, USA, 8-9 November 1989, published by ASTM, Philadelphia, USA, pp 320-339 


\section{ANNEX A}

\section{DETERMINATION OF LOAD-LINE DISPLACEMENT}

\section{A.1. Correction Procedure for Extraneous Displacements}

As noted in Section 6, values of $\mathrm{J}$ must be determined from the area under the load versus loadline displacement diagram. To accurately deternine load-line displacement, it is necessary to take account of indentation effects, pin penetration, machine stiffness etc. These extraneous displacements are additive, so that measurements derived from machine crosshead displacement, or relative displacements between the specimen and the testing machine will overestimate the true load-line displacement. The degree of overestimate will vary with material, temperature, loading rate, specimen dimensions, loading fixtures and test machine.

A test configuration as shown in Fig. A.1a or A.1b using identically prepared, but unnotched, samples is used to generate a load-displacement correction curve. This correction curve is then subtracted from the load-displacement curve obtained during the actual fracture test with notched samples. This subtraction is performed by subracting the correction curve displacement from the fracture test displacement at corresponding loads.

(a)

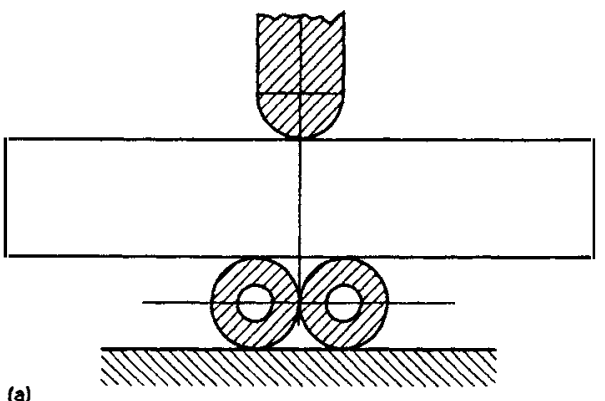

(b)

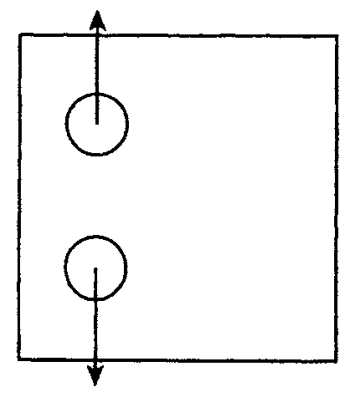

Fig. A.1. Arrangements for determining indentation displacement

(a) SENB specimen

(b) CT testpiece 
In practice, a linear correction curve can usually be obtained (up to the maximum loads ricorded in the fracture test). Use of a linear correction simplifies the displacement correction. An $y$ initial non-linearity due to penetration of the loading pins into the sample is observed during toth the calibration test and the actual fracture test, so a linearisation of the near-zero correction data and. the fracture test data can effectively correct for this initial non-linearity.

The indentation tests should be carried out at the same loading rate as the fracture test, i.e. normally $1 \mathrm{~mm} / \mathrm{min}$.

The corrected energy $U$ for each specimen is calculated from integrating the appropriate load versus load-point displacement diagram as illustrated in Fig. A.2a and correcting for indentation, using the curve in Fig. A.2b.

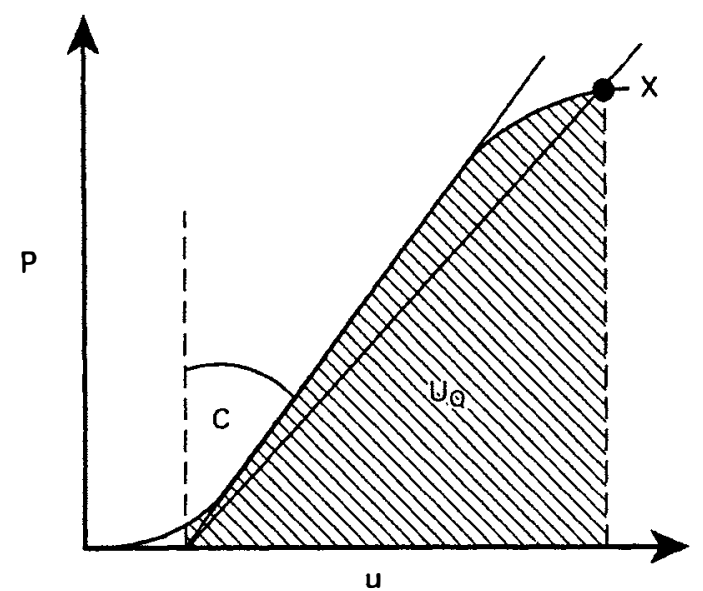

(a)

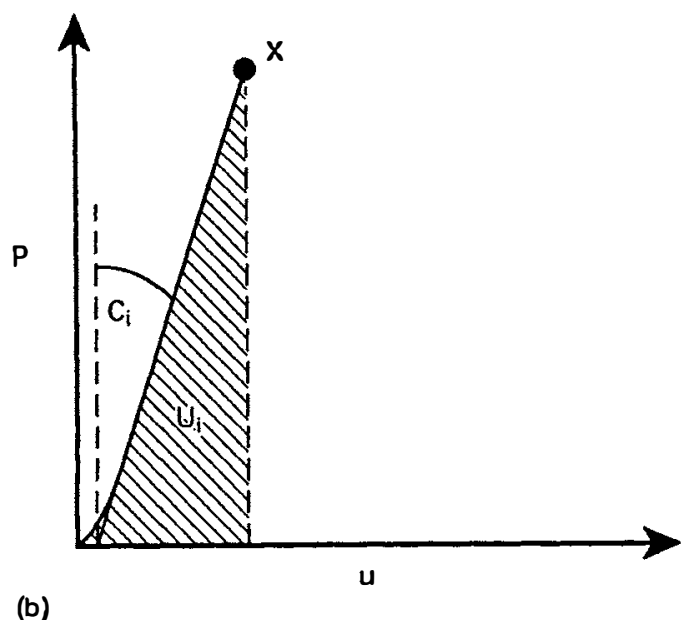

Fig. A.2. Method of correcting for indentation

(a) Load - deflection: fracture test

(b) Load - deflection: indentation 
The corrected fracture energy is given by:

$\mathrm{U}=\mathrm{U}_{\mathrm{Q}}-\mathrm{U}_{\mathrm{i}}$

Total energy corrections are usually $<20 \%$.

The fracture resistance, J, may then be calculated from U using Eq. (1) in the text of this protocol.

Further details of these correction procedures are given in the LEFM standard for plastics [Ref.4 in protocol above].

\section{A.2. Use of a Comparator Bar}

The only way to obtain load-line displacement directly in a SENB specimen is to measure the relative movement of appropriate points on the spocimen. For example, one can measure the vertical displacement of the notch tip relative to a horizontal line that is a fixed distance from the undeformed edge of the specimen near the outer loading points. This type of direct measurement may be obtained by using a horizontal comparator bar [Ref. A.1.] and determining the vertical displacement of the bar relate to the notch tip or notch mouth as shown in Fig. A.3.

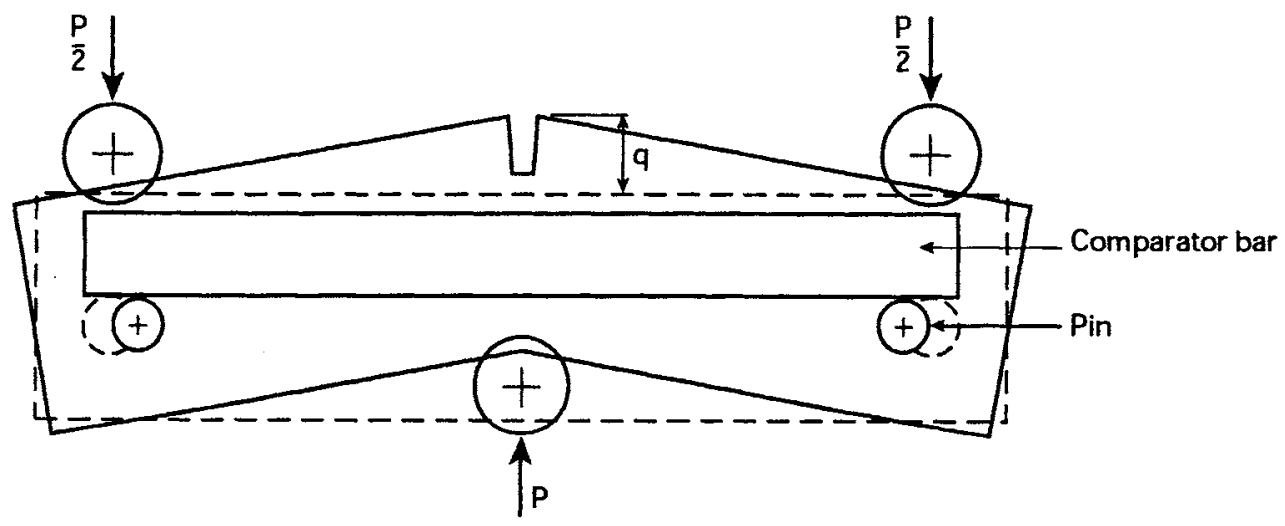

Fig. A.3. Principle of comparator bar measurement

\section{A.3. References}

A.1. Dawes, M. G: (1977). Elastic-plastic fracture toughness based on the COD and J-contour integral concepts, In: ASTM STP 668, Symposium on Elastic-plastic Fracture, p. 607. 


\section{ANNEX B}

\section{CRACK LENGTH MEASUREMENT}

B.1. A major source of error with these tests can occur with measurement of the final crack front on the testpiece. There is a need to establish unambiguously which region on the fracture face is characteristic of actual crack growth in the test.

B.2. There are a number of methods available for breaking open a specimen so that the amount of crack growth that occurs during the test can be deternined more precisely. These are:

i. high speed impact with or without prior cooling (in either solid carbon dioxide $\left\{-70^{\circ} \mathrm{C}\right\}$ or liquid nitrogen), to produce a brittle fracture;

ii. high rate fatigue cycling - interference with any existing craze/process zones should be considered:

Useful results can be obtained if the sample is fatigued over a load range between 25 and $75 \%$ of the highest load achieved in the fracture test. Generally, room temperature cycling is adequate. However, for tougher materials, it may be useful to fatigue the specimen whilst it is cooled below ambient temperature. The crack should be propagated by at least $0.2 \mathrm{~mm}$ by fatigue, although greater amounts of fatigue crack growth are acceptable. To finally break the testpiece open, it should be reloaded at the same rate as the original fracture test (i.e. typically $1 \mathrm{~mm} / \mathrm{min}$ ) to give a smooth fracture face.

iii. injection of inks or dyes into the crack before breaking open - surface tension may be a problem here;

iv. two-step cooling - initially in solid carbon dioxide and later in liquid nitrogell.

B.3. Problems which have been identified are:

i. Direct immersion in liquid nitrogen for 5 minutes prior to breaking open may, in some cases, cause the specimen to shatter. This can often be avoided by making a sawcut through the back face opposite to the crack to a depth of approximately $5 \mathrm{~mm}$. The sample is then cooled using solid carbon dioxide (i.e. to around $-70^{\circ} \mathrm{C}$ ) for 5-10 minutes, after which it can be reloaded in the test rig and broken open. A further refinement is to fit a spacer (e.g. a broken piece of sawblade) irto the sawcut before reloading so that the back face cannot close up and the amcunt of bending in the remaining ligament is reduced. With both these approaches, the compressive strain at the back face is reduced and this tends to minimise the risk of the material shattering.

ii. The appearance of additional features, e.g. half-moon shapes on the fracture face, has been noted (Fig. B.1.). These are probably a function of the cooling and breaking open cycle given to the specimen. 


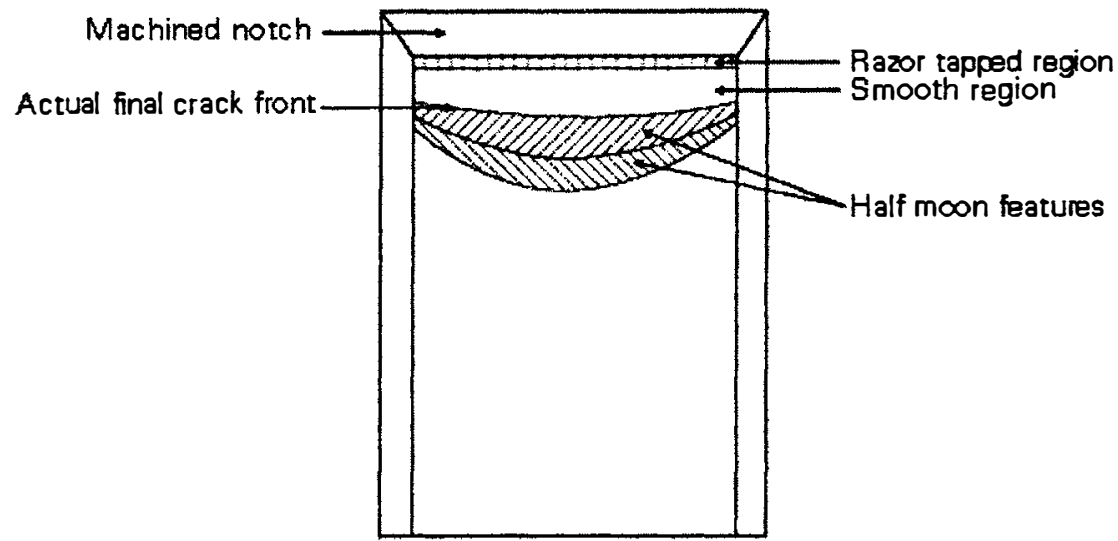

Fig. B.1. Possible features observed on polymer fracture faces after cooling in liquid nitrogen

iii. Additional features are likely if the material under test tends to exhibit multiple cracking ahead of the principal crack tip, e.g. polypropylene, and this can make interpretation of the fracture face more difficult.

To assess the influence of both the latter points, an additional precracked but untested sample should be broken open. This will help to indicate which features are characteristic of the cooling/breaking open operation for each polymer.

B.4. Where possible, optical or low magnification SEM photographs of the fracture faces should be taken and included with the report.

B.5. It is suggested that a fine bandsaw is employed to section a specimen midway through its thickness (Fig. B.2.). The cut face is then polished on successively finer grades of emery or silicon carbide to at least a 600 grit finish.
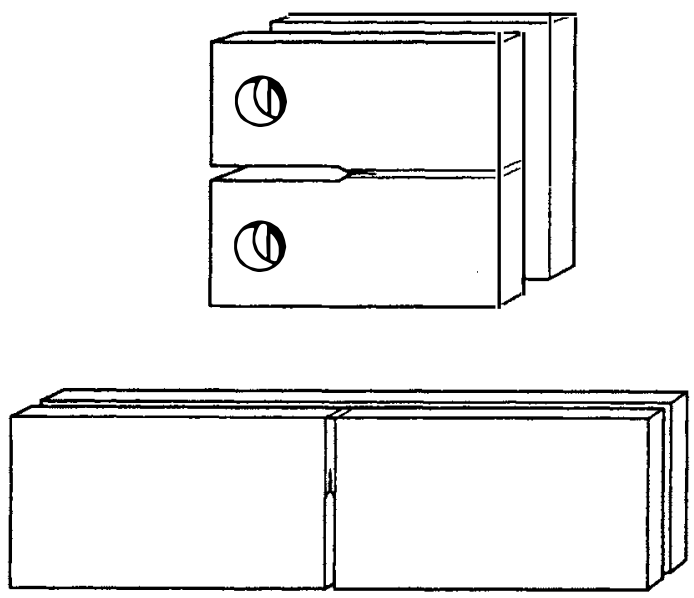

Fig. B.2. Diagram to show sectioning procedure for compact tension and single edge notch bend specimens 
B.6. A reliable measurement of crack growth on a sectioned specimen can only be obtained if the crack is wedged fully open. This can be done by inserting a wedge into the crack mouth (Fig. B.3) after loading the testpiece to at least $80 \%$ of the total displacement reached in the test.

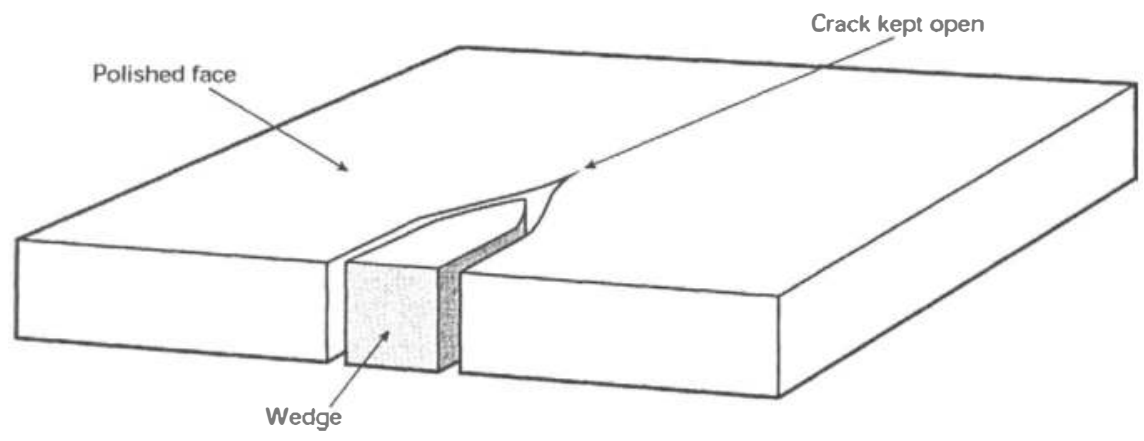

Fig. B.3. Use of a wedge to open crack tip

B.7. Altematively, a small three-point loading rig can be used in which the load is applied by tightening a screw which forces the crack faces apart. (Further information on this type of rig can be obtained from Phil Marshall of Pipeline Developments or Roy Moore at ICI).

B.8. The crack growth on the section should be measured using either a travelling microscope or a high power optical microscope. 


\section{ANNEX C}

\section{Reporting form for $\mathbf{J} \mathbf{R}$-curve tests on plastics}

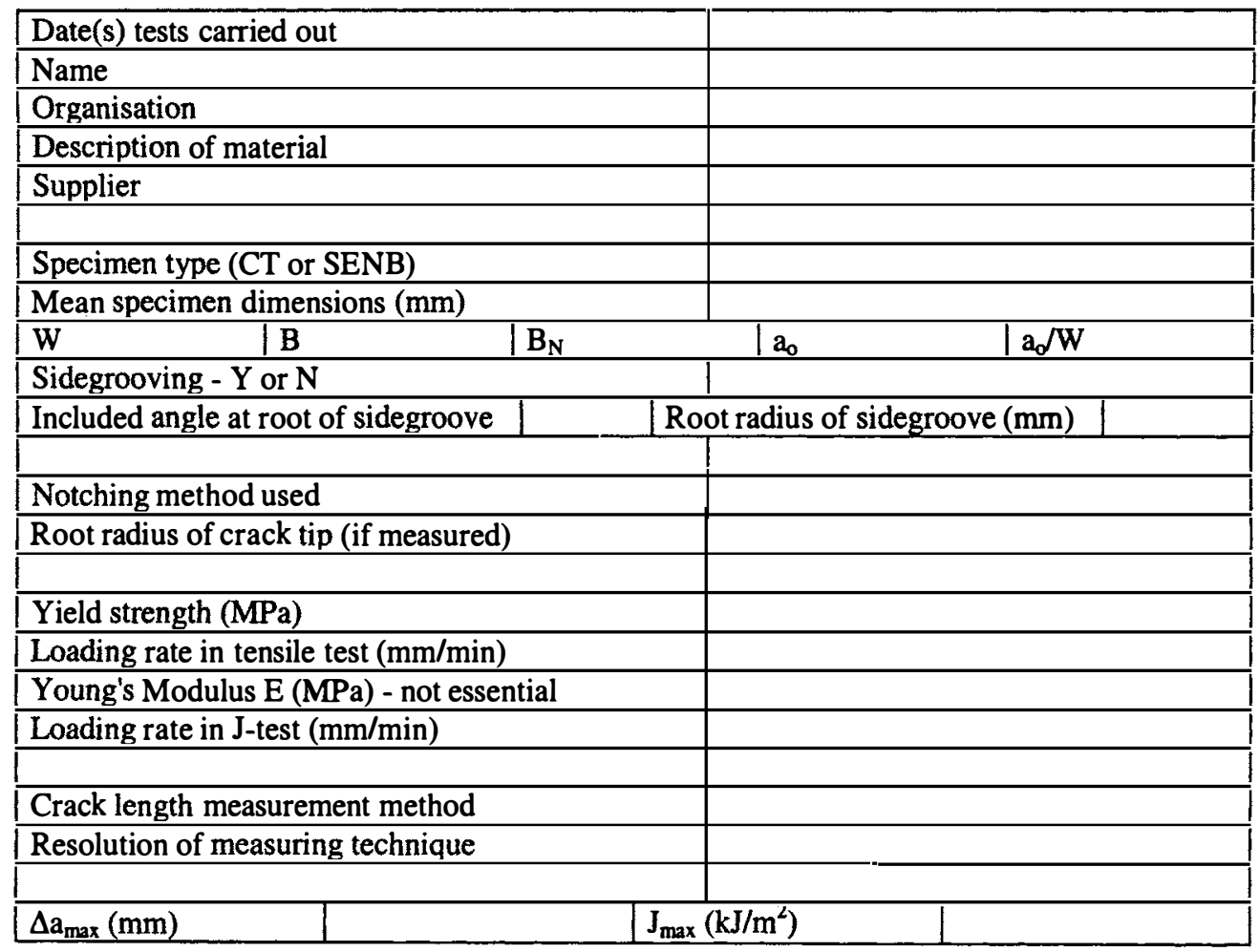

\begin{tabular}{|l|l|l|l|l|l|l|l|l|l|l|}
\hline Specimen No. & 1 & 2 & 3 & 4 & 5 & 6 & 7 & 8 & 9 & 10 \\
\hline \begin{tabular}{l}
$J\left(\mathrm{~kJ} / \mathrm{m}^{2}\right)$ \\
\hline$\Delta \mathrm{a}(\mathrm{mm})$
\end{tabular} & & & & & & & & & & \\
\hline $\begin{array}{l}\text { Used for curve } \\
\text { fitting (Y/N)? }\end{array}$ & & & & & & & & & & \\
\hline $\begin{array}{l}\text { Brittle fractures or } \\
\text { pop-ins' (Add Y } \\
\text { against relevant } \\
\text { specimen) }\end{array}$ & & & & & & & & & & \\
\hline
\end{tabular}

\begin{tabular}{|c|c|c|}
\hline Power law & $\mathrm{A}$ & \\
\hline $\mathrm{J}_{0.2}\left(\mathrm{~kJ} / \mathrm{m}^{2}\right)$ & & $\operatorname{Valid}(\mathrm{Y} / \mathrm{N}) ?$ \\
\hline $\mathrm{J}_{\mathrm{BL}}\left(\mathrm{kJ} / \mathrm{m}^{2}\right)$ & & Valid $(\mathrm{Y} / \mathrm{N}) ?$ \\
\hline
\end{tabular}

